Document downloaded from:

http://hdl.handle.net/10251/97780

This paper must be cited as:

García-Arias, A.; Francés, F. (2016). The RVDM: modelling impacts, evolution and competition processes to determine riparian vegetation dynamics. Ecohydrology. 9(3):438459. doi:10.1002/eco.1648

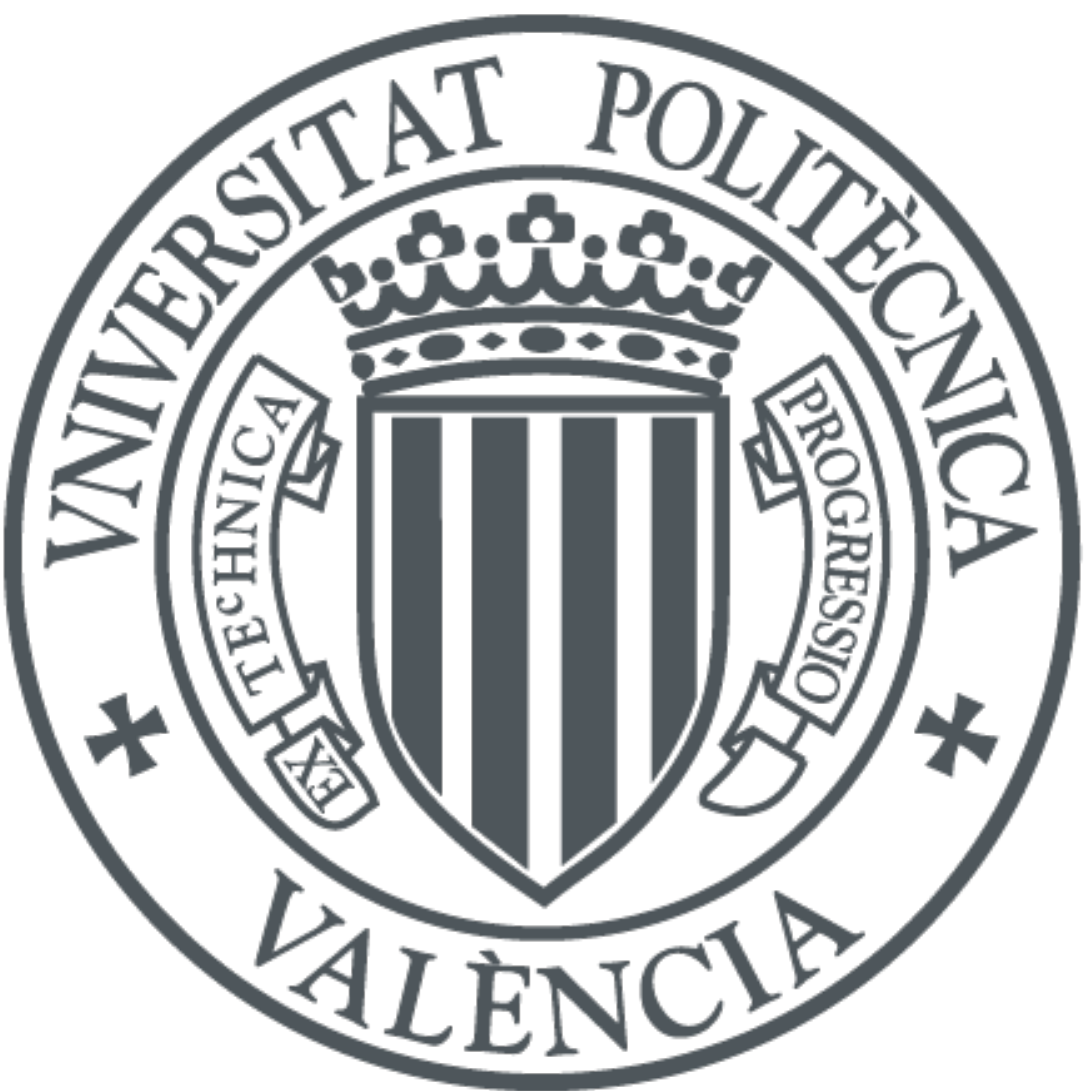

The final publication is available at

http://doi.org/10.1002/eco.1648

Copyright John Wiley \& Sons

Additional Information 
This is a pre-copyedited, author-produced PDF version following peer review of the article: García-Arias A. and Francés F. 2016. THE RVDM MODEL: MODELLING IMPACTS, EVOLUTION AND COMPETITION PROCESSES TO DETERMINE RIPARIAN VEGETATION DYNAMICS. Ecohydrology. Volume 9, Issue 3, Pages 438-459. DOI: 10.1002/eco.1648, which has been published in definitive publisher-authenticated form in April 2016 at http://onlinelibrary.wiley.com/doi/10.1002/eco.1648/abstract Article published online June 2015 by John Wiley \& Sons, Ltd. All rights reserved. All further use of this material other than for personal research is subject to permission from the publisher.

\title{
THE RVDM MODEL: MODELLING IMPACTS, EVOLUTION AND COMPETITION PROCESSES TO DETERMINE RIPARIAN VEGETATION DYNAMICS
}

\author{
ALICIA GARCIA-ARIAS AND FELIX FRANCES \\ Research Institute of Water and Environmental Engineering, Universitat Politècnica de València, Camí de \\ Vera s/n 46022 Valencia, Spain
}

\begin{abstract}
RVDM is an ecohydrological model aimed to study the vegetation dynamics in riparian areas that represents an upgrade respect to previous tools in the way of understanding the riparian dynamics. Important novelties are proposed by this tool, including a high temporal resolution (daily time step), a proposal of a new plant classification approach useful for research and management (successional plant functional types or SPFTs), good representation of the key processes that determine the vegetation dynamics in riparian areas (drought and flood impacts, recruitment, growth, succession and competition), an easy implementation, and feasible inclusion of river morphodynamics in the model implementation (including different daily elevation and soil maps in the inputs). The model implementation in a Mediterranean semi-arid study site resulted satisfactorily (cell by cell calibration accuracy $\geq 65 \%$, cell by cell validation accuracy between $40 \%$ and 60\%), demonstrating the great potential of this approach for future research and management applications. Although 36 parameters are included in the model conceptualization, the global sensitivity analysis demonstrated that only 8 types of parameters are actually influent.. These parameters are: minimum time since mixed for transition to terrestrial, root depths, transpiration factors, critical shear stress of early stages, minimum biomass required to allow succession, germination minimum capillary water content in the upper soil, effective depth considered for evaporation from bare soil and coverage of pioneers. RVDM model will be a useful tool for gaining a better understanding of the riparian plants behaviour under different ecohydrological conditions.
\end{abstract}

\section{INTRODUCTION}

The study of vegetation dynamics in riparian areas represents a tight research line within the Ecohydrology science. In semi-arid Mediterranean riparian areas, the vegetation distribution and its wellbeing is almost exclusively linked to the river hydrodynamics. Different modelling approaches have arisen in the recent past (e.g. Hooke et al., 2005; Camporeale and Ridolfi, 2006; Perona et al., 2009; Benjankar et al., 2011; Maddock III et al., 2012; García-Arias et al., 2013; Ye et al., 2013; García-Arias et al., 2014). However, more research is required to gain a better reproducibility of the vegetation behaviour on riparian ecosystems. Some models relate the vegetation dynamics on the riparian areas to the floodplain morphodynamics (e.g. Hooke et al., 2005; Coulthard et al. 2007). However, there is still a necessity of quantitative modelling approaches that better represent the coupling between the riparian vegetation dynamics with the river morphological changes (Camporeale et al., 2013). 
Impacts caused by river-driven disturbances, mainly intensity, duration, extent and frequency of floods, droughts and groundwater fluctuations, control the riparian vegetation dynamics (Tabacchi et al., 1998; Rood et al., 2003; Camporeale and Ridolfi, 2006; Corenblit et al., 2007). Floods can modify the riparian spatial patterns massively and are essential for maintaining the ecological integrity, health, resilience, and productivity of the riparian plant communities (Naiman et al., 2008; Merrit et al., 2010). In semi-arid environments, the water scarcity is an additional hydrological limiting factor responsible for the vegetation stress (Porporato et al., 2001; Rodríguez-Iturbe and Porporato, 2004). As floods and droughts often represent crucial causes of mortality, both exert selective pressure for adaptation (Lytle and Poff, 2004; Naumburg et al., 2005; Naiman et al., 2005, 2008). In consequence, most of the riparian plants have mechanisms to withstand a certain degree of impact caused by scour, root asphyxia and wilt stress. Critical thresholds can be determined for each case, so that the vegetation is considered removed completely or damaged to death when these limits are exceeded (Benjankar et al., 2011; García-Arias et al., 2013). Disturbances can trigger a secondary succession but also a recovery of the previous vegetation. In consequence, in this paper we propose a significant advance over previous work, which is to assume that partial damages over the pre-existing vegetation should be considered in addition to critical impacts, and that the magnitude and duration of the event on one hand, and the existing canopy characteristics on the other, are the main factors that determine the impact grade and extent.

In semi-arid environments, the natural evolution of the vegetation is mainly controlled by the water accessibility (Laio et al., 2001). In the riparian zones, the dispersal and germination of seeds and the maintenance of soil moisture to allow the plant establishment depend on river flows (Mahoney and Rood, 1998; Lite et al., 2005; Gurnell et al., 2008; Greet et al., 2011). Even when a successful recruitment occurs, hydrological processes are still key determinant for growth, long term survival and mortality (Stromberg and Patten, 1991; Merrit et al., 2010).

Plants evapotranspiration capabilities have been reported as valid criterion for measuring the vegetation growth and productivity efficiency (Quevedo and Francés, 2008), as indicator of optimum environmental conditions for different types of vegetation (Porporato et al., 2001), and as predictor of the vegetation spatial distribution in riparian areas (García-Arias et al., 2014). All these considerations suggest that taking into account the estimation of the evapotranspiration in the vegetation evolution prediction is more than recommendable in deterministic modelling approaches. Although water use efficiency has been used to evaluate biomass production in relation to water transpired, also in riparian species (Cao et al., 2012), the light use efficiency (LUE) should not be ignored in primary production estimations (Yuan et al., 2007; Polley et al., 2011; Collati et al., 2014; Pasquato et al., 2014). Plants age coupled with river flow hydrodynamics have been already used for the evaluation of succession/retrogression vegetation dynamics in riparian areas (Benjankar et al., 2011; Formann et al., 2013; García-Arias et al., 2014). However, the primary biomass production should be included among those modelling criteria for the determination of the vegetation evolution patterns (Douma et al., 2012). Developing quantified relationships between hydrological variables and the riparian vegetation metrics for vegetation prediction in space and time requires making difficult choices (Merrit el al., 2010). Major simplifications are frequently required to allow the models implementation on different case studies. However, access to light and water is limited in riparian areas of semi-arid environments. Since both are two essential resources, modelling approaches should consider the specific plant competition processes that take place on these environments. The competition is in many cases determinant for the recruitment and the evolution of the possible succession lines (Hood and Naiman, 2000; Corenblit et al., 2014).

The aim of the present study was to develop a new model that integrates the knowledge provided by previous tools and that represents an upgrade in the way of understanding the relations between the riparian hydrodynamics and the vegetation dynamics. Furthermore, implementation in a Mediterranean semi-arid study site, and sensitivity analysis of the model were conducted with satisfactory results, demonstrating the great potential of this approach for future research and management applications. This paper is divided into 3 main sections. In the first part we glance over a general overview of the model components, that are further described in more detail including their mathematical conceptualization. A second part is destined to review the model implementation process and the obtained results in the case study. In a third section, a multicriteria sensitivity analysis of the model variables to the parameters is presented. To conclude, we focus the discussion on the advantages and limitations of the proposed modelling approach so we can draw, in the final section, some conclusions that summarize the model reliability, the possible applications, the most important weaknesses and the main strengths of our approach to the problem.

\section{THE RVDM MODEL}

\section{General model description}

The RVDM (Riparian Vegetation Dynamic Model) is the result of integrating the computations of the impacts over the vegetation established in the river banks, the evolution of this vegetation and its competition with other potential plant types. Through a daily time step and a fine spatial resolution (usually 
between 0.5 and 2 meters as explained in García-Arias et al., 2014), this distributed model allows analysing in detail the vegetation dynamics in riverine areas of semi-arid environments. The cell size has to be a compromise between the vegetation patch and elevation spatial variabilities.

The river dynamics direct effects over the riparian vegetation wellbeing and distribution are considered as well as the impacts caused by changes in the river morphology. RVDM considers the evolution of the vegetation under the effect of the hydrological extremes in terms of plant removal or biomass loss, depending on the degree of the impact. In addition, the model analyses how the river hydrodynamics and morphodynamics set conditions for the recruitment on impacted areas, the vegetation growth, the succession or retrogression between different successional stages and the competition between succession lines.

The RVDM model has a modular structure (Figure 1). The main state variable of the model is the successional plant functional type (SPFT) that occupies each cell or pixel. The SPFTs meet the classification requirements of a functional type approach with similar taxonomical and ecological characteristics. Moreover, since succession/retrogression schemes are required for the different modules, the SPFTs have been proposed as different phases of three possible succession lines: riparian reed, riparian cottonwood and terrestrial (Benjankar et al., 2011; García-Arias et al., 2013). Additionally, an estimation of the biomass related to each cell is a complementary state variable. Both, SPFT and biomass, represent the main input and output of each module.

The first of the three modules that make up RVDM is the impacts module. Through this module, RVDM is capable to translate the stress caused by flood or droughts events into changes on the plant biomass (including full removal) and, consequently, on the SPFTs distribution. Firstly, consequences of a flood event are established by means of the removal related to the water shear stress. Afterwards, the effects of asphyxia and wilt are established based on the estimation of the water content in the capillary storage of the soil and the duration of the stress. The second module is the evolution module and includes three submodules named recruitment, growth and succession/retrogression. The recruitment succeeds if the seeds presence, the germination of those seeds and the seedling establishment occur properly. The occurrence of these three stages depends on the plant reproductive period and on specific environmental conditions requirements (temperature, oxygen, moisture and light). The vegetation growth is established in terms of biomass increase or decrease through a light use efficiency (LUE) model. Following the approach proposed by Pasquato et al. (2014), the LUE model adopted for the RVDM definition simulates gross primary production as a function of intercepted light and light use efficiency, the ratio between the unstressed canopy carbon assimilation rate and the photosynthetically active radiation (PAR) absorbed by the canopy. To include the reduction of the LUE under a water stress situation, the evapotranspiration index defined by Garcia-Arias et al. (2014) is included as factor of plant transpiration reduction when soil moisture is a limiting factor. The succession/retrogression affects each succession line independently; changes between succession lines and transitions are analysed in the competition module. Within a succession line, each SPFT has associated age spans and minimum biomass to determine the succession and retrogression changes. Finally, the competition between riparian succession lines and between the riparian and the terrestrial vegetation is analysed through the competition module. This third module considers changes between successional patterns and transitional areas establishing the most suitable SPFT through their transpiration capabilities under the same conditions. The three main modules of RVDM interact with a fourth module of water balance.

The model implementation is easy since the data requirements are limited and accessible in many case studies. A vegetation map of SPFTs is required as initial condition. A second vegetation map of biomass can be provided to the model as initial condition. However, this map is not indispensable since internal rules allow the estimation of the initial biomass based on the SPFTs map. Other daily, both aggregated and distributed, inputs are required. These inputs must describe correctly the morphology, the pedology and the hydraulics of the river reach under study through reliable maps: digital elevation model (DEM), soil types, and shear stress $(\tau)$ and water table elevation $\left(Z_{w t}\right)$ maps related to reference discharges. In addition, hydro-meteorological and geographical variable time series are required, including precipitation $(P)$, temperatures $\left(T_{\max }, T_{\min }\right)$, daily flow $\left(Q_{d}\right)$ and maximum instantaneous discharge $\left(Q_{i}\right)$, reference evapotranspiration $\left(E T_{0}\right)$, photosynthesis active radiation $(P A R)$ and seed release periods $\left(S_{r}\right)$. To complete the RVDM inputs, some vegetation and soil parameters have to be defined. The model results consist of daily vegetation maps of SPFTs and biomass, which are considered as new inputs in the next model iteration, as shown in Figure 1. In the next sections we will describe with more detail the main state variable and the different sub-modules of RVDM. 


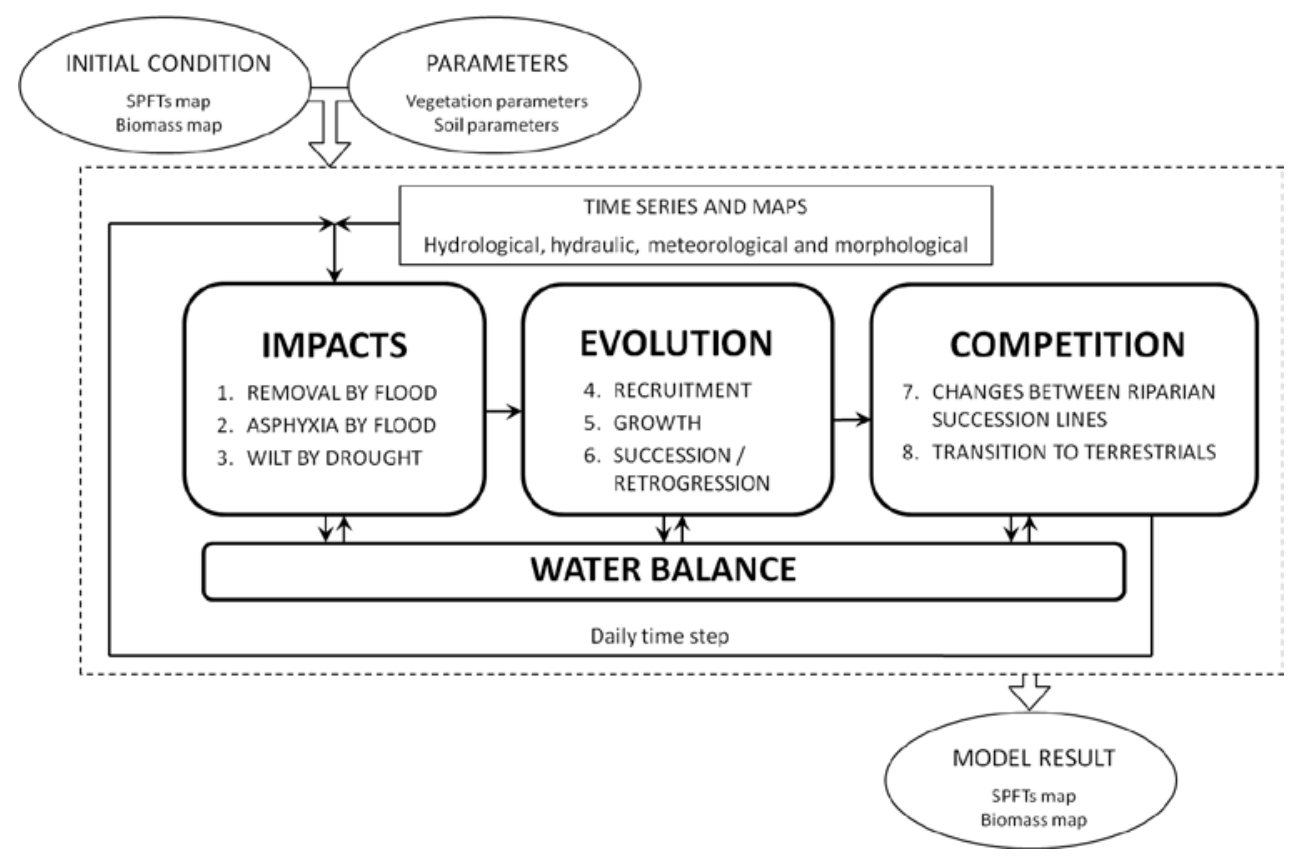

Figure 1. General schema of RVDM defined as the ensemble of the impacts, evolution and competition modules and sub-modules.

\section{Successional plant functional types (SPFTs)}

As explained before, the SPFT is the main state variable of RVDM. The proposed SPFTs are related to the reed and cottonwood riparian succession lines, and to a terrestrial succession line considered the zonal vegetation that would occupy the riparian areas if the river disturbances disappeared (Figure 2).

Every succession lines shares an initial SPFT absent of vegetation or bare soil (BS). The potential settlement condition starts when there is presence of reed, cottonwood or terrestrial seeds (PS $S_{R E C}, P S_{C W} C$ and PSTVC respectively). The pioneer SPFTs ( $P_{R E}, P_{C W}$ and $P_{T V}$ respectively) correspond to germinated vegetation. Although germination in riverine areas is commonly very productive, most of the seedlings die during the first year as consequence of summer droughts in semi-arid environments (Mahoney and Rood, 1998). For this reason, RVDM requires not only a successful germination but also a successful recruitment of the pioneers. The recruitment is considered successful when the establishment of the seedlings takes place. Only then, the vegetation becomes an herbaceous SPFT ( $\mathrm{H}_{\mathrm{RE}}, \mathrm{H}_{\mathrm{c} w}$ and $\mathrm{H}_{\mathrm{TV}}$ respectively). The reed succession line ends with this $H_{R E}$. Once $H_{R E}$ is reached, the model considers that the light conditions are optimum for the recruitment of the cottonwood series (shadowing from the reeds). If the cottonwood "wins" the competition, the SPFTs evolve to this succession line. The following SPFTs for the cottonwood and terrestrial succession lines are the woody SPFTs ( $W_{C W}$ and $W_{T V}$ respectively). A transitional SPFT between $W_{C W}$ and $W_{T V}$ has been defined as the woody mixed vegetation SPFT $\left(W_{M V}\right)$. When $W_{M V}$ occurs, the environmental conditions are analysed to determine if the cottonwood or the terrestrials are allowed to win the competition for the area. Otherwise, the $\mathrm{W}_{\mathrm{MV}}$ persists. Once the $\mathrm{W}_{\mathrm{TV}}$ is reached the competition is no more considered. On the contrary, the terrestrial vegetation is considerably more sensitive to river disturbances. In consequence, the riparian vegetation has the opportunity to colonize the impacted areas when the environmental conditions change from suitable to terrestrials to favourable to riparian.

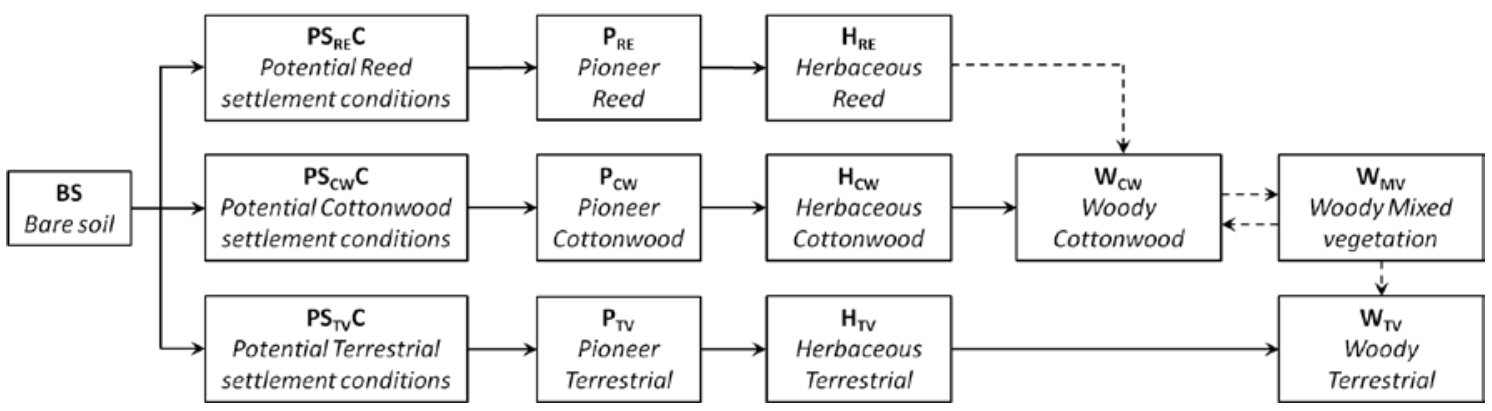

Figure 2. Successional plant functional types (SPFTs). Different succession lines correspond to different rows. Among each line, growth stages are sequentially defined by arrows. Dotted arrows indicate 
transitional stages or changes between succession lines.

\section{Water balance module}

The water content in the soil determines the vegetation transpiration capabilities and the asphyxia conditions. In riparian areas, it is also important to consider the accessibility to the water table and the plant capacities to use the water from the saturated zone of the soil. Taking this into account, through balance equations similar to those used in the RibAV model (García-Arias et al., 2014), the capillary water in the upper soil at the end of the day $(H)$ and the actual transpiration $(T)$ can be estimated. Comparing the daily values of these two variables to several vegetation parameters, the RVDM modules establish the changes on the SPFTs and biomass state variables. RVDM improves the RibAV approach of water balance in the soil by considering the interception of a part of rainfall water by the plants, Int, and the evaporation from the bare soil, $E$, (Figure 3). In RibAV, water was considered to be extracted only by transpiration from the unsaturated upper soil, $T_{u}$. The evaporation of the interception, $E_{i}$, is also incorporated.

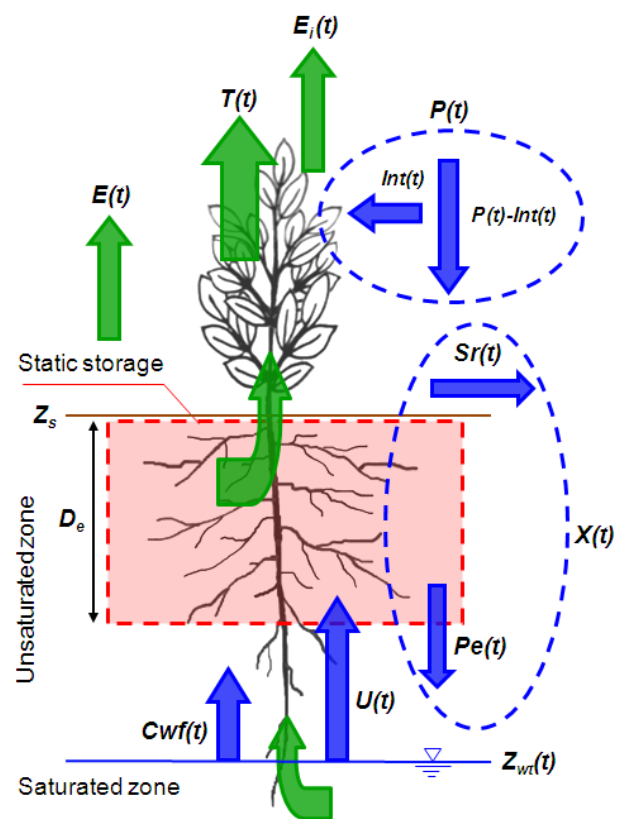

Figure 3. Internal and external water fluxes of one cell in the RVDM model that represent an improved version of the general conceptualization of the RibAV model (García-Arias et al., 2014).

The unsaturated upper soil tank dimensions are defined by the effective root depth, $D_{e}$. Since the water content in this soil layer $(H)$ ranges between field capacity $H_{f c}$ and wilting point $H_{w p}$, water can be extracted from the unsaturated upper soil only by plant transpiration and by evaporation. The water content at the end of day $t$ is given by the next discrete (not differential) balance equation:

$$
H(t)=H(t-1)+I(t)-T_{u}(t)-E(t)
$$

where $I(\mathrm{~mm})$ represents the water inputs to the unsaturated upper soil. The water inputs $I$ and the excess water $X(\mathrm{~mm})$ can be calculated by balance, considering the local precipitation, the initial abstractions and the contributions from the saturated zone:

$$
\begin{aligned}
& I(t)=P(t)-\operatorname{Int}(t)+I_{s}(t)-X(t) \\
& X(t)=P(t)-\operatorname{Int}(t)+I_{s}(t)-H_{f c}+H(t-1)
\end{aligned}
$$

where $P(\mathrm{~mm})$ is the precipitation, Int $(\mathrm{mm})$ is the interception, $I_{s}(\mathrm{~mm})$ represents the contributions from the saturated zone, and $H_{f c}(\mathrm{~mm})$ is the upper limit of $H$. Campbell's soil-water retention curve is used in order to calculate water contents from reference pressures (Campbell, 1974). 
$H(t)=\left(\frac{\psi_{b}}{\psi(t)}\right)^{\lambda} \phi D_{e}$

where $\lambda$ is the pore size distribution index, $\Phi$ is the soil porosity, $\Psi(\mathrm{kPa})$ is the capillary pressure of the soil and $\psi_{\mathrm{b}}(\mathrm{kPa})$ is the bubbling pressure. For the calculation of $H_{f c}$, a reference field capacity point pressure $\left(\Psi_{f c}\right)$ is considered as $33 \mathrm{kPa}$ for all soil types.

The reference evapotranspiration, $E T_{0}(\mathrm{~mm})$, is used as the maximum potential evapotranspiration of the system. It is considered to be consumed sequentially in the evaporation of the interception, the transpiration and finally in the bare soil evaporation:

$$
E_{i}(t)+T(t)+E(t) \leq E T_{0}(t)
$$

The interception limited by the daily precipitation, the interception tank capacity and the remaining water intercepted and not evaporated from the previous day:

$$
\operatorname{Int}(t)=I_{S S C} C v-(\operatorname{Int}(t-1)-E i(t-1))
$$

where $I_{S s C}$ and $C v$ are vegetation parameters, specific storage capacity $(\mathrm{mm})$ and vegetation coverage factor respectively.

Following the RibAV modelling approach (García-Arias et al., 2014), two main fluxes from the saturated zone are considered in RVDM (Figure 3): the hydraulic lift $(U)$ and the upward capillary water flow (Cwf). The root system is required to be in contact with the water table elevation, $Z_{w t}$, to allow these fluxes from the saturated zone. The presence of roots is enclosed by the maximum root depth, $D_{r}$. To analyse the interaction between the vegetation and the abiotic factors it is necessary to refer this $D_{r}$ and the effective root depth, $D_{e}$ to $Z_{s}$. The derived parameters are, respectively, the maximum root depth elevation, $Z_{r}$, and the effective root depth elevation, $Z_{e}$.

The hydraulic lift, understood as root water uptake $(\mathrm{mm})$, takes place only when the root system is connected to the saturated zone during the night. As explained by García-Arias et al. (2014) it is given by:

$$
U(t)=-\operatorname{Cr} h_{n}\left(\psi_{\mathrm{fc}}-\psi(t)\right) r_{s} \frac{1}{1+\left(\psi(t) / \psi_{50}\right)^{3.22}}
$$

where, for each cell, $h_{n}$ corresponds to 10 hours of nighttime, $\Psi_{50}(\mathrm{kPa})$ is the midpoint saturation pressure that corresponds to a relative soil moisture of $50 \%$ and $r_{s}$ corresponds to the value of the transpiration factor from the saturated zone. Ryel et al. (2002) estimated the value of $\mathrm{Cr}$ as $0.97 \mathrm{~mm} \mathrm{MPa}^{-1} \mathrm{~h}^{-1}$, and this value has been consolidated in other studies, in particular in Zheng and Wang (2007).

The consideration of Cwf is limited by a minimum depth to consider upward capillary water flow from the water table to the unsaturated upper soil $\left(D_{c}\right)$. This depth, referred to $Z_{s}$, corresponds to the minimum elevation, $Z_{c}(\mathrm{~m})$, to allow the capillary rise to the unsaturated upper soil. Within its boundary, the Cwf calculation depends on the relative position of the water table respect to the root depths. There is a first case of effective root connectivity $\left(Z_{w t} \geq Z_{e}\right)$ in which the Cwf is assumed to be enough to fill the unsaturated upper soil tank up to field capacity:

$$
C w f(t)=H_{f c}-H(t-1)-U(t)
$$

This value represents the maximum limit of $\mathrm{Cwf}(\mathrm{mm})$.

When there is root connectivity but it is out of the boundaries of the effective root depth, the calculation of Cwf considers the hydraulic conductivity of the unsaturated soil, $K\left(\mathrm{~mm} \mathrm{~h}^{-1}\right)$ :

$$
K(t)=\left(\frac{\psi_{b}}{\psi(t)}\right)^{3 \lambda+2} K_{s}
$$

were $K_{s}\left(\mathrm{~mm} \mathrm{~h}^{-1}\right)$ is the hydraulic conductivity of the saturated zone.

In this case of $Z_{e}>Z_{w t}>Z_{r}$, two values are required to be included as dimensional corrections. In order to transform the capillary pressure value into meters, $0.102 \mathrm{~m}$ water column $\mathrm{kPa}^{-1}$ is used. In addition, hourly conductivity of the unsaturated soil has to be corrected by $24 \mathrm{hd}^{-1}$. Taking this into account, the Cwf 
calculation is given by:

$$
C w f(t)=\left[\left(\frac{-0.102 \cdot \psi(t)}{Z_{w t}(t)-Z_{e}}\right)-1\right] \cdot 24 K(t)
$$

$T(\mathrm{~mm})$ is calculated by the addition of two transpiration components that take place in riparian areas: the transpiration from the unsaturated zone, $T_{u}(\mathrm{~mm})$, and transpiration from the saturated zone, $T_{s}(\mathrm{~mm})$. The optimum pressure for plant transpiration, $\psi^{\star}(\mathrm{kPa})$, is defined as the pressure in the moment before the plant begins to have water availability limitations, while the wilting point pressure, $\psi_{\mathrm{wp}}(\mathrm{mm})$, is considered to be the limit that suspends the transpiration. Additionally, $T_{u}$ is only possible if the plant is not under asphyxia conditions. The asphyxia root depth, $D_{a}(\mathrm{~m})$, sets the upper limit of the water table elevation tolerated by plants. The asphyxia root depth elevation, $Z_{a}(\mathrm{~m})$, is compared to $Z_{w t}(\mathrm{~m})$ to determine if the plant is or is not under asphyxia conditions. $T_{u}$ is possible if $Z_{a}>Z_{w t}$ and if the capillary water in the upper soil is enough to allow the plant its extraction, i.e. if $H>H_{w p}$. Under this situation, there are two possible cases to be considered for its estimation. In a first case of effective connectivity between the root system and the saturated zone $\left(Z_{e} \leq Z_{w t}\right), T_{u}$ is proportional to the relative water availability between $Z_{w t}$ and $Z_{a}$, and the vegetation coverage factor, $C v$, and the transpiration efficiency from the unsaturated zone factor, $r_{u}$, are taken into account for its estimation:

$$
T_{u}(t)=r_{u} \cdot C v \cdot\left(E T_{0}(t)-E_{i}(t)\right) \cdot\left(1-\frac{Z_{w t}-Z_{e}}{Z_{a}-Z_{e}}\right)
$$

In the second case, without effective connectivity $\left(Z_{e}>Z_{w t}\right), T_{u}$ is determined by the relative capillary water content in the upper soil, $H_{\text {rel }}(\mathrm{mm})$ :

$$
H_{r e l}(t)=\operatorname{Min}\left(\frac{H(t-1)-H_{w p}}{H^{*}-H_{w p}} ; 1\right)
$$

Considering no restrictions for transpiration at optimum moisture content conditions in the soil ( $\left.\vartheta^{*}\right)$, a linear reduction while moisture decreases, and taking into account the complete cease under wilting point moisture $\left(\vartheta_{w p}\right)$ conditions, $T_{u}$ is calculated by:

$$
T_{u}(t)=r_{u} c v\left(E_{0}(t)-E_{i}(t)\right) H_{r e l}(t)
$$

For the occurrence of $T_{s}$ it is required that the root system is connected to the water table $\left(Z_{r} \geq Z_{w t}\right)$ and there has to be remaining potential evapotranspiration. Under these assumptions, $T_{s}$ is calculated by:

$$
T_{s}(t)=\operatorname{Min}\left(c v\left(E_{0}(t)-E_{i}(t)\right)-T_{u}(t) ; r_{s} c v\left(E_{0}(t)-E_{i}(t)\right) Z_{r e l}(t)\right)
$$

where $Z_{r e l}(m)$ is the relative depth of the saturated zone when the potential evapotranspiration is not limiting, which is given by:

$$
Z_{r e l}= \begin{cases}\left(\frac{Z_{w t}(t)-Z_{e}}{Z_{a}-Z_{e}}\right) & \text { if } Z_{a}>Z_{w t}(t) \geq Z_{e} \\ \left(\frac{Z_{w t}(t)-Z_{r}}{Z_{e}-Z_{r}}\right) & \text { if } Z_{e}>Z_{w t}(t) \geq Z_{r}\end{cases}
$$

Finally, the actual transpiration, $T$, is calculated as the addition of $T_{u}$ and $T_{s}$ :

$$
T(t)=T_{u}(t)+T_{s}(t)
$$

The calculation of the bare soil evaporation, $E$, is necessary for the establishment of the $H(t)$ by the end of the day $t$. It is calculated considering the remaining capillary water in the upper soil after the transpiration 
from the vegetated area and the lower limit set by the $H_{w p}$ :

$$
E(t)=\left[\mathrm{ET}_{0}(\mathrm{t})-\mathrm{E}_{\mathrm{i}}(\mathrm{t})\right](1-\mathrm{cv}) \beta(H)
$$

where $\beta$ is a linear soil water limitation function in the capillary storage defined by the effective depth, $D_{b s e}$ $(\mathrm{m})$, for bared soil water content evaporation:

$$
\beta(H)=\mid \begin{array}{ll}
1 & \text { for } I(t)+H(t-1)-T_{u}(t) \geq H^{*} \\
\frac{I(t)+H(t-1)-T_{u}(t)-H_{w p}}{H^{*}-H_{w p}} & \text { for } H_{w p}<I(t)+H(t-1)-T_{u}(t)<H^{*} \\
0 & \text { for } I(t)+H(t-1)-T_{u}(t) \leq H_{w p}
\end{array}
$$

\section{Impacts module}

The impacts module includes three sub-modules that establish the biomass reduction or the plant death as consequence of hydrological stress. These three sub-modules analyse sequentially the removal by flood, the asphyxia by flood and the wilt by drought.

\section{Removal by flood sub-module}

For every time step, the distributed shear stress, $\tau\left(\mathrm{N} \mathrm{m}^{-2}\right)$, is calculated by means of the interpolation between reference $\tau_{j}$ maps, associated to reference maximum instantaneous flows, $Q_{i, j}\left(\mathrm{~m}^{3} \mathrm{~s}^{-1}\right)$ :

$$
\tau(t)=\tau_{\mathrm{j}-1}+\left(\frac{Q_{i}(t)-Q_{i j-1}}{Q_{i j}-Q_{i j-1}}\right) \cdot\left(\tau_{\mathrm{j}}-\tau_{\mathrm{j}-1}\right)
$$

This $\tau$ is compared to the specific minimum shear stress $\left(\tau_{m}\right)$ and critical shear stress $\left(\tau_{c}\right)$ tolerated by the vegetation to determine if there is biomass removal. The vegetation is considered to be not affected under $\tau(t)<\tau_{m}$ conditions. In consequence, there is not biomass reduction. On the contrary, $\tau(t)>\tau_{c}$ are considered as complete plant removal conditions. Under this situation the biomass is cancelled, the area is considered bared and the SPFT is set as BS. The model considers a linear reduction on the biomass of the SPFT if $\tau_{m}<\tau(t)<\tau_{c}$. The biomass remain is calculated as $B_{T}(t)=B(t-1) \cdot \xi_{\tau}(t)$, where $\xi_{\tau}(t)$ is given by:

$$
\xi \tau(\mathrm{t})=\frac{\tau(t)-\tau_{c}}{\tau_{\mathrm{m}}-\tau_{c}}
$$

\section{Asphyxia by flood sub-module}

Similarly, the daily water table elevation, $Z_{w t}(\mathrm{~m})$, is estimated by the interpolation of the reference $Z_{w t, j}$ maps associated to reference daily flows, $Q_{j}\left(\mathrm{~m}^{3} \mathrm{~s}^{-1}\right)$ :

$$
\mathrm{Z}_{\mathrm{wt}}(t)=\mathrm{Z}_{\mathrm{wt} j-1}+\left(\frac{Q(t)-Q_{j-1}}{Q_{j}-Q_{j-1}}\right) \cdot\left(Z_{w t j}-Z_{w t j-1}\right)
$$

The soil saturation generates anaerobic conditions that can cause plant physiological damages as leaf shedding and complete plant loss if the damage is severe. The asphyxia root depth elevation, $Z_{a}$, represents a threshold for asphyxia conditions when it is exceeded by $Z_{w t}$. No impact is considered if $Z_{w t}<Z_{a}$. On the contrary, different types of damage are considered when $Z_{w t}>Z_{a}$. Not only the depth but also the flood duration can be related to the degree of damages caused by physiological asphyxia (Brinson and Verhoeven, 1999; Tabacchi et al., 2005; García-Arias et al., 2014). In consequence, two vegetation parameters that represent the minimum, $a_{m}$, and the critical, $a_{c}$, number of consecutive days under asphyxia conditions, delimit the biomass loss. There are three possible plant behaviors under asphyxia considering these thresholds (Figure 4). 


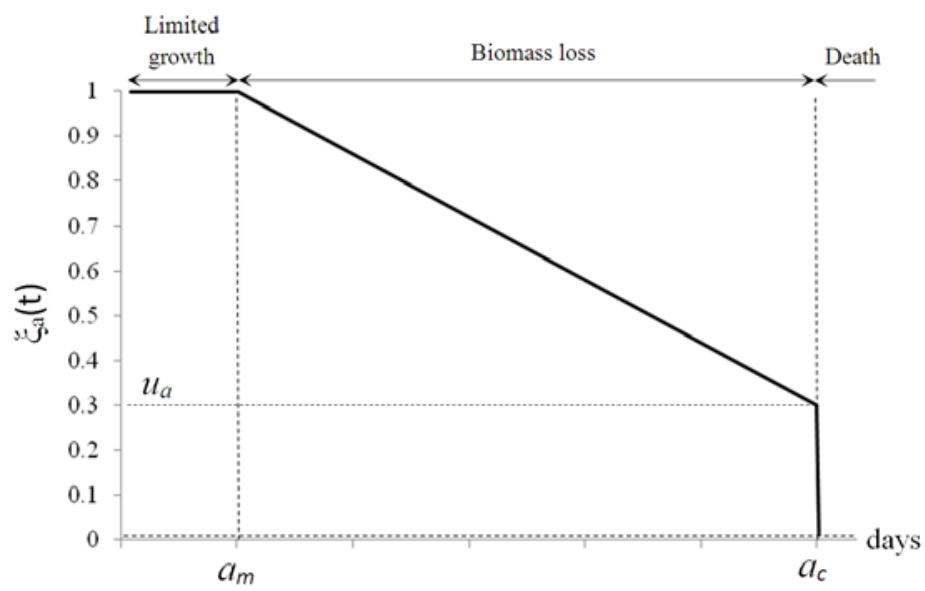

Figure 4. Biomass loss estimation under asphyxia by flood in RVDM considering different thresholds: the minimum $\left(a_{m}\right)$ and the critical $\left(a_{c}\right)$ number of consecutive days under asphyxia conditions and the minimum relative remain of biomass $\left(u_{a}\right)$ that leads to plant death.

The aerobic respiration is considered not possible under asphyxia situation although $a(t)<a_{m}$. In consequence, the model prevents the biomass growth. However, since the minimum limit is not exceeded biomass loss is not considered to occur under this situation. The model considers differently a $a_{m}<a(t)<a_{c}$ situation. Under this condition, the biomass decreases linearly to a minimum relative remain of biomass, $u_{a}$ that leads to plant death. The biomass remain after the impact is calculated as $B_{a}(t)=B_{T}(t) \cdot \xi_{a}(t)$, where $\xi_{a}(t)$, is given by:

$\xi_{\mathrm{a}}(t)=\frac{a(t)+u_{a}\left[a_{m}-a(t)\right]+a_{c}}{a_{m}-a_{c}}$

The complete plant loss is considered to occur when $a(t)>a_{c}$, the area becomes bared and the SPFT is set as BS.

\section{Wilt by drought sub-module}

RVDM considers the occurrence of wilt stress when the plant transpiration is null. A plant considered affected by wilt closes its stomata and halts the transpiration, $T(t)=0$. This is a resistance mechanism that allows vegetation to afford wilt stress during a limited time period. The number of consecutive days with no transpiration determines the biomass loss. RVDM considers $w_{m}$ as the minimum number of consecutive days under wilt stress to induce biomass loss. Until this $w_{m}$, the wilt stress is considered to cause the cease of the plant growth. Thereafter, the biomass loss is considered linear until a relative minimum boundary of biomass, $u_{w}$, that leads to plant death. The remaining biomass is estimated as $B_{w}(t)=B_{a}(t) \cdot \xi_{w}(t)$, where $B_{a}(t)$ has been calculated in the previous sub-module, and $\xi_{w}(t)$ is given by:

$$
\xi_{w}(t)=\frac{w(t)+u_{w}\left[w_{m}-w(t)\right]+w_{c}}{w_{m}-w_{c}}
$$

were $w_{c}$ is the critical number of consecutive days under wilt stress that causes plant death. This threshold is included to consider the irreversible wilt stress by drought. As occurs in previous sub-models, under this critical situation the model assumes the plant death; the area becomes bared and sets the SPFT as BS.

\section{Evolution module}

The evolution module is based on processes that can be grouped in three sub-modules: the vegetation recruitment, its growth and the succession or retrogression between SPFTs.

\section{Recruitment sub-module}

The successful recruitment is modelled considering three main requirements: the presence of available seeds, the successful germination of those seeds and the successful establishment of the seedlings. For Mediterranean cottonwood species the dispersal capacity, both through anemochory and hydrochory, is not limiting for the recruitment (Guilloy-Froget et al., 2002; González et al., 2010). On the contrary, the presence/absence of available seeds in other riparian species is determined by the occurrence of floods (Boedeltje et al., 2004; Neff and Baldwin, 2005, Gurnell et al., 2008, Greet et al., 2011), and in consequence the flood seasonal timing must be considered in process based models. In RVDM, autumn 
floods are considered destructive for both riparian succession lines, in terms of removal of the available seeds. In consequence, when peak flows occur during the autumn-winter period the potential settlement areas are considered to retrogress to BS conditions (bare soil with absence of seeds). Once the spring season is initiated, the seed release is assumed for cottonwood and terrestrials and the model considers that the bare soil evolves to the PSC (potential settlement condition) successional stage. The seed release is considered for reed after the occurrence of a spring flood. In fact, a minimum spring instantaneous flow, $Q i_{s r}$, has to be overload to allow seed release of the succession series Reed. The germination process is controlled by temperature, moisture, oxygen and light. Through the establishment of representative germination parameters, and comparing the related variable values for each time step, the germination is set profitable or non-profitable for PSC areas. The germination process parameterization includes the interval of temperatures ( $\left.T_{\text {gmax }}, T_{\text {gmin }}\right)$ in which the germination is possible. On each time step, the maximum and minimum temperatures $\left(T_{\max }(t), T_{\min }(t)\right)$ are compared to the interval and in the cases when it is higher or lower the germination is directly dismissed. The oxygen availability is the next step to be analysed in case of temperature within the interval. A water table elevation above the soil surface $\left(Z_{w t}(t)>Z_{s}\right)$ is considered to be responsible of anoxia and implies that the germination does not occur. On the contrary, with available oxygen $\left(Z_{w t}(t) \leq Z_{s}\right)$ the germination is considered allowed and the module analyses the moisture conditions. A parameter that represents the minimum moisture required for germination is set as minimum water content for germination, $H_{\text {gmin. }}$. While water stress prevents the germination, a favourable soil moisture situation leads the module to analyse the light limitations. The photosynthetically active radiation (PAR) is used as variable to determine the germination success. While some riparian species require light exposure for their establishment and development (heliophytes), other would rather behave better under shadowed areas (esciophytes). The riparian succession lines classification allows a distinction between both types so in RVDM the cottonwood line is established as esciophyte and the reed is considered heliophyte. Consequently a unique parameter is required to determine which succession line germination is possible in terms of light conditions, the PAR threshold between esciophytes and

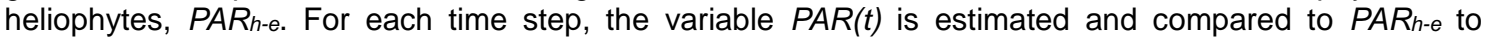
determine if the light conditions allow the germination of the cottonwood or the reed. The terrestrial series is not considered to be limited by light conditions since it includes different species behaviour. Impossibility of germination by any of the limiting variables results in cells maintained as PSC. The areas where the germination (CW-TV or RE-TV) is not limited are finally considered as areas where the germination has been successful and the pioneer SPFT is achieved. However, the successful recruitment is not considered assured yet. Although germination stage is commonly very productive, most of the seedlings die during the first year as consequence of summer droughts in semi-arid environments (Mahoney and Rood, 1998). For this reason, RVDM requires not only a successful germination but also a successful recruitment of the pioneers that depends on the summer. The recruitment of each succession line only is considered possible if there was a previous successful germination and if the number of days necessary for establishment, $N D E$, is achieved. The successful establishment of the seedlings depends on the sum of the actual transpiration of the pioneers, $\Sigma T$, and on the time since germination occurred, TSG. There is a competition analysis during the recruitment module. While the competition between riparian succession lines depends on the presence of seeds and the limiting environmental variable is the light during the germination process, the competition between riparian and terrestrial succession lines is established by comparison of the accumulated actual transpiration of each pioneer since the germination. When TSG>NDE and $\Sigma T$ of one line is higher than the other, the herb SPFT corresponding to the most favourable succession line is achieved. In those cases where the germination is successful but the recruitment is not, the simulated SPFT is $P$ if the plant still resists or BS if the plant dies. On the contrary, if the recruitment succeeds, the areas are simulated as herbs $\left(\mathrm{H}_{\mathrm{RE}}, \mathrm{H}_{\mathrm{CW}}\right.$ or $\left.\mathrm{H}_{\mathrm{TV}}\right)$. The result of the recruitment sub-module is a map of SPFTs and a map of biomass. The biomass in this sub-module is only corrected with minimum values for those cells where a successful germination or establishment occurs.

\section{Growth sub-module}

The vegetation growth is evaluated if there have not been impacts at the time step under analysis. Under this assumption, on every vegetated area, the biomass growth is estimated. Although a simply logistic curve has been considered as suitable approach for riparian vegetation biomass production estimations (Perucca et al., 2006; Ye et al., 2013), in RVDM the logistic growth approach is integrated in a LUE model through the leaf allocation factor, $\varphi_{l}$, which is calculated by:

$\varphi_{l}(t)=1-\frac{L A I(t)}{L A I_{\max }}$

While $L A I_{\text {max }}$ is a model parameter that represents the maximum LAI that can occur in an ecosystem, LAI $\left(\mathrm{m}^{2}\right.$ green leaf $\mathrm{m}^{-2}$ ground) is the leaf area per ground area, variable and function of the specific leaf area factor, SLA $\left(\mathrm{m}^{2} \mathrm{gC}^{-1}\right)$, the biomass and the coverage: 
Through the proposed LUE model, the response of each vegetated area can be categorized as normal growth, retarded growth or biomass loss. RVDM analyses quantitatively this biomass growth or loss through discrete biomass estimation for the time step on each cell:

$$
\frac{d B}{d t}=\left(L U E \cdot E T_{i d x}(t) \cdot A P A R(t)-\operatorname{Re}(t)\right) \cdot \varphi_{l}(t-1)-k_{a} \cdot B(t-1)
$$

where LUE is the light use efficiency ( $\left.\mathrm{gC} \mathrm{MJ}^{-1} \mathrm{APAR}\right)$ for each SPFT, $k_{a}$ is the leaf natural decay factor $\left(\mathrm{d}^{-1}\right)$ and APAR (MJ m$\left.~^{-2} \mathrm{~d}^{-1}\right)$ is the absorbed photosynthetically active radiation, which is calculated through the multiplication of the PAR and the FPAR. FPAR $\left(\mathrm{MJ} \mathrm{m}^{-2} \mathrm{~d}^{-1}\right)$ is the fraction of incident PAR absorbed by the canopy estimated with a Beer-Lambert law:

$$
\operatorname{FPAR}(t)=0.95\left(1-e^{-l_{e} L A I(t-1)}\right)
$$

where $l_{e}$ is the light extinction coefficient over foliage elements.

The $\mathrm{E}_{\mathrm{idx}}$ is the daily evapotranspiration index (García-Arias et al., 2014) is given by:

$$
E T_{i d x}(t)=\frac{T(t)}{c v E T_{0}(t)-E_{i}(t)}
$$

Finally, the maintenance respiration $\left(R e, \mathrm{~kg} \mathrm{DM} \mathrm{m}^{-2} \mathrm{~d}^{-1}\right.$ ) is based on tissue specific C:N ratios, air temperature, tissue biomass and phenology (Sitch et al., 2003). Following this approach, RVDM includes in the respiration calculation a modified Arrhenius equation for the temperature dependence of respiration rates, and a leaf C:N ratio equal to 29 (Sitch et al., 2003). Adjusting the biomass to the leaf carbon mass, 1 $\mathrm{g} \mathrm{C}$ in $2.2 \mathrm{~g}$ oven-dry organic matter, the respiration is estimated by:

$$
\operatorname{Re}(t)=\left(\frac{r r B(t-1)}{2.2 \cdot 29}\right) \cdot e^{308.56\left[\left(\frac{1}{56.02}-\frac{1}{T_{\text {med }}+46.02}\right)\right]}
$$

where, $T_{\text {med }}$ is the average temperature $\left({ }^{\circ} \mathrm{C}\right), r r$ is the respiration rate $\left(\mathrm{gC} \mathrm{g}^{-1} \mathrm{~N} \mathrm{~d}^{-1}\right)$.

\section{Succession/Retrogression sub-module}

Considering each succession line independently, the possible successions and the retrogressions are studied. Changes between succession lines and transitions are analysed in the competition module. Among a succession line, each pioneer, herbaceous and woody SPFT has associated a minimum biomass, $\mathrm{B}_{\text {min, }}$ and a living span. This living span is defined by the parameters $A_{g} e_{s}$, that represents the minimum age (days) that the previous SPFT requires for the succession to the SPFT, and Age max, which is defined as the maximum age (days) that results on plant death if the $B_{\min }$ of the following SPFT is not reached, or what is the same, if the succession is at a standstill. Successions from herbs to woody SPFTs in the cottonwood and in the terrestrial succession lines occur when $A g e_{s}$ and $B_{\min }$ thresholds are exceeded. Retrogression occurs when a SPFT achieves a maximum age considered limiting for survival. The retrogression is assumed by ageing in woody SPFTs. On the contrary, the aging is qualified by the impossibility to gain biomass enough to evolve to more advanced succession stages on pioneers and herbaceous SPFTs. The result is the plant death and the resulting SPFT is BS. In this first version of the RVDM model three hypotheses are assumed. By the first one this module omits retrogressions caused by biomass loss; these retrogressions are established in the impacts module and result in BS. In consequence, there is no chance of retrogressions from $\mathrm{H}$ to $\mathrm{P}$ or from $\mathrm{W}$ to $\mathrm{H}$. The second assumption considers dormancy of the seeds unlimited in time. Consequently, PSC cannot suffer retrogression in this sub-module. Finally, the evolution from BS to PSC, then to $\mathrm{P}$, and finally to $\mathrm{H}$ is analysed in the recruitment sub-module, saving the necessity to analyse these successions here. In consequence, the lower limit of the herbs SPFTs lifespan is defined by the vegetation parameter NDE of the recruitment sub-module.

\section{Competition module}

The competition module analyses separately the competition between the riparian succession lines and the natural transition from riparian communities to terrestrials when hydrological disturbances are not 
enough to maintain the riparian dynamics. In consequence two sub-modules are proposed: changes between riparian succession lines and transition to terrestrials.

\section{Changes between riparian succession lines sub-module}

The shadow from the reeds, in $\mathrm{H}_{\mathrm{RE}}$ areas, is considered by the model as optimum light conditions for the recruitment of the cottonwood series. Under this assumption, the presence of seeds and other limiting environmental conditions are analysed to determine if the cottonwood can establish in each reed cell. As it is defined in the recruitment sub-module, temperature, oxygen, and soil moisture can lead on a dismissed germination in this module. When no environmental limitations take place, the model considers different combined SPFTs stages that are "transparent" to the user. The first of these internal stages represents the potential coexistence when cottonwood seeds ( $P S_{C W C}$ ) are present on reed areas ( $\left.H_{R E}\right)$. After the cottonwood seeds germinate $\left(\mathrm{P}_{\mathrm{cw}}\right)$, the coexistence stage begins in the area. Each stage is maintained for the next time step until the following is possible. The last stage is reached at NDE and corresponds to the competition between the reed herbs ( $\left.\mathrm{H}_{\mathrm{RE}}\right)$ and the established cottonwood herbs $\left(\mathrm{H}_{\mathrm{cw}}\right)$. During these intermediate stages, cottonwood seeds, pioneers and herbs are considered to be protected by the reeds to face impacts. In consequence, no retrogressions of cottonwoods are assumed in these stages until impacts affect the reeds or the cottonwood wins the competition.

When establishment is assumed and the cottonwood recruitment is considered successful, the sub-module analyses the competition itself for every time step. The critical variable for comparison is the actual accumulated transpiration $(\Sigma T)$ considered the total number of days since competition. $\Sigma T$ is calculated for both $\mathrm{H}_{\mathrm{RE}}$ and $\mathrm{H}_{\mathrm{CW}}$ under the same conditions of the cell. Reeds are maintained until $\mathrm{H}_{\mathrm{CW}}$ "wins" the competition $\left(\Sigma T(t) \mathrm{H}_{\mathrm{RE}}<\Sigma T(t) \mathrm{H}_{\mathrm{CW}}\right)$ and the biomass satisfies the $B_{\text {min }}$ limitation for $\mathrm{W}_{\mathrm{CW}}$. The result under this case is a change in the SPFT of the cell from $\mathrm{H}_{\mathrm{RE}}$ to $\mathrm{W}_{\mathrm{CW}}$. The competition is then considered finished.

\section{Transition to terrestrials sub-module}

The mature stage of the cottonwood series is considered to evolve naturally to the terrestrial series when no hydrological perturbations take place. Indeed, riparian systems can be considered as transitional semiterrestrial areas (Naiman et al., 2005). Flood disturbances are the main driver of change in the riparian communities, but they are not the only ones. There are other constraints to be considered under semi-arid conditions, especially droughts frequency, intensity and duration. In these environments, the capabilities of the riparian plants to transpire from different water sources can make a difference when there is not enough capillary water in the upper soil but the water table is accessible. The RVDM model incorporates the analysis of the water use through transpiration calculations to determine if the terrestrial species are allowed to start the competition for the area. The variable used for comparison is the accumulated evapotranspiration index, $\Sigma E T_{i d x}$, as indicator of the wellbeing trend, dependant on the transpiration capabilities of the different SPFTs that can potentially occupy the area. The competition between cottonwoods and terrestrials is only analyzed on $\mathrm{W}_{\mathrm{CW}}, \mathrm{W}_{\mathrm{MV}}$ and $\mathrm{W}_{\mathrm{TV}}$ areas and in two transitional steps. The minimum age required for transition parameter, called $A g e_{T}$, defines the timing for cottonwood areas while all transitional areas are analyzed. In consequence, in a first step the competition between $W_{\mathrm{cW}}$ and $\mathrm{W}_{\mathrm{MV}}$ SPTFS is analyzed in every area occupied by $\mathrm{W}_{\mathrm{MV}}$ and in areas that have been occupied by $\mathrm{W}_{\mathrm{CW}}$ longer than $A g e_{T}$. The result can be both, $\mathrm{W}_{\mathrm{CW}}$ and $\mathrm{W}_{\mathrm{MV}}$ so this first step is a two-way approach. On the contrary, the second step only considers the potential transition from $\mathrm{W}_{\mathrm{MV}}$ to $\mathrm{W}_{\mathrm{TV}}$. The competition analysis in this case is limited by a second timing parameter, $t_{\min T v}$ that defines the minimum number of days since $\mathrm{W}_{\mathrm{MV}}$ to enable the transition to $\mathrm{W}_{\mathrm{TV}}$. Once the area has been occupied by $\mathrm{W}_{\mathrm{MV}}$ for longer than $t_{\min T V}$, the $\Sigma E T_{\text {idx }}$ for both potential SPFTs is compared iteratively until $W_{T V}$ wins the competition.

\section{MODEL IMPLEMENTATION STRATEGY}

\section{General overview}

The parameters were iteratively optimized manually until the model was considered correctly calibrated for the study site. This optimization process was performed after the results obtained from $2.510^{5}$ Monte Carlo simulations were compared and the effective ranks of parameters were identified. Several complementary temporal periods were analysed in the study site to validate the model. The model was considered correctly implemented when the results for the objective functions in the calibration and the validation periods were satisfactory and comparatively better than previous models implemented in the same study site for comparable periods (García-Arias et al., 2013; García-Arias et al., 2014).

\section{Case study}

One study site has been selected for the model performance evaluation in semi-arid riparian conditions, the Terde reach (Mijares River, Spain). Terde is a $230 \mathrm{~m}$ long reach near to natural conditions with no canalization or flow regulation. It is located at 850 metres above the sea level and it has an accumulated basin area of $665 \mathrm{~km}^{2}$. The substrate of the reach is varied and dominated by fine gravels, gravels, cobbles and some scattered boulders. The riparian corridor is continuous and connected with the terrestrial vegetation areas. The three succession lines analyzed by RVDM are sufficiently represented. 
The reed line is dominated by common reed in its herbaceous SPFT, while cottonwood is dominated by willows and poplars, and terrestrial is dominated by oaks and junipers in most of the SPFTs. This is a strong reason why Terde has been selected among other reaches for the model testing.

The selected periods withdraws the intra- and inter-annual variability of the discharges that is characteristic in Mediterranean semi-arid watersheds. The flow in Terde is permanent, with a $0.86 \mathrm{~m}^{3} / \mathrm{s}$ mean annual discharge (for available data between 1948 and 2009). Extraordinary floods between 300 and $650 \mathrm{~m}^{3} / \mathrm{s}$ instantaneous flows have been observed in this site. Unfortunately, the aerial photographs used to create the vegetation inputs need to be necessarily of better quality than those available for the earlier years. In consequence, a period from 2000 to 2009 was considered for the model implementation. A calibration period between July 1, 2000 and August 31, 2006 was considered and the map obtained from the July 1, 2000 aerial photograph was given to the model as initial SPFTs condition. The validation periods were established from August 31, 2006 to December 31, 2009 and from July 1, 2000 to December 31, 2009. The periods ending in 2009 were considered especially interesting for the model performance evaluation. While the calibration period does not present extraordinary floods, during the periods used for the model validation, two floods were registered in the last three years of simulation (a flood of $342 \mathrm{~m}^{3} / \mathrm{s}$ maximum instantaneous river flow in September 11, 2006 and another $300 \mathrm{~m}^{3} / \mathrm{s}$ flood in August 9, 2009).

\section{Model inputs}

The hydro-meteorological inputs had been obtained for a previous study (García-Arias et al., 2014) from raw data provided by different national and local institution services. In consequence, daily precipitation $(P)$, daily maximum and minimum temperatures $\left(T_{\max }, T_{\min }\right)$, daily potential evapotranspiration $\left(E T_{0}\right)$, daily and maximum instantaneous river flow $\left(Q_{d}\right.$ and $\left.Q_{i}\right)$, and the average monthly shortwave radiation $\left(R_{S}\right)$ were already available for the study site. PAR daily values were obtained, considering a constant ratio of 0.48 MJ PAR/MJ Rs (McCree, 1972).

In our case study, the elevation spatial variability is restrictive for the cell size selection and $1 \mathrm{~m}$ cells were needed to obtain a good representation of the topography in the riparian zone. A digital elevation model, sixteen reference maps of water table elevation from 0 to $150 \mathrm{~m}^{3} \mathrm{~s}^{-1}\left(Z_{w t, j}\right)$, the soils map used (ten different soil types) and the corresponding set of parameters for each soil type were available and have been described intensively by García-Arias et al. (2014). Similarly, distributed shear stress reference maps related to maximum instantaneous peak flows between 2.5 and $650 \mathrm{~m}^{3} \mathrm{~s}^{-1}$ were obtained by means of the relation with the shear velocities $\left(u^{*}[\mathrm{~m} / \mathrm{s}]\right), \tau=\rho \cdot u^{\star 2}$, where $\rho$ is the water density $\left(\mathrm{kg} \mathrm{m}^{-3}\right)$ as explained by García-Arias et al. (2013).

\section{State variable observations and initial condition}

The SPFTs maps generation, required the identification of patches of different vegetation types in the correspondent aerial photographs. These patches were categorized by means of the information collected on field during 2009 (García-Arias et al., 2013) and through expert rules considering colour, texture, coverage and other subjective qualities of the aerial photograph patches. Three SPFTs maps were obtained, representative for the vegetation communities' distribution on July 1, 2000, August 31, 2006 and December 31, 2009.

For every period analysed, the model generated the initial biomass condition relating the initial SPFTs map with the minimum biomass parameters $\left(B_{\min }\right)$ defined in the Succession/Retrogression sub-module. A compromise solution was adopted for the SPFTs with no assignment of $B_{\min }$. For pioneer areas the initial biomass was set as half the $B_{\min }$ of the herb SPFT of the same succession line. For $\mathrm{W}_{\mathrm{MV}}$ areas the initial biomass was set as average of $B_{\min }$ for $\mathrm{W}_{\mathrm{CW}}$ and $B_{\min }$ for $\mathrm{W}_{\mathrm{TV}}$.

\section{Vegetation model parameters initial estimation}

The vegetation parameters were defined with enclosed ranges of values (Table 1) for the further analysis of the model response (implementation process and sensitivity analysis). These ranges bounds were defined based on previous experience using preceding models in the same case study (García-Arias et al., 2013; García-Arias et al., 2014) and other literature references. Cv was analyzed ranging between 0.2 and 1 (e.g. Maddock III and Baird, 2003; Scott et al., 2003), while $\psi^{*}$ and $\psi_{w p}$ ranged between 200 and 3000 $\mathrm{kPa}$ (e.g. Guymon, 1994; Laio et al., 2001) being the lower values considered for optimal pressure of riparian pioneers and the higher for wilting point pressures of the most resistant to drought SPFTs as WTV. The ranges for parameters related to root depths, $D_{r}, D_{e}$ and $D_{a}$, varied considerably between SPFTs. Since the references for riparian vegetation are scarce and not very specific (e.g. Canadell et al., 1996; Schenk and Jackson 2002; Baird and Maddock III, 2005; Webb and Leake, 2006; Padilla and Pugnaire, 2007), the ranges considered were not very constraining. Following the consideration of deeper roots for more advanced stages and considering the physiological differences between the riparian and the terrestrial plants, $D_{r}$ ranges were set between 0.1 and 20.0 metres and $D_{e}$ obtained values between 0.05 and 3.0 metres. Different ranges for $D_{a}$ were defined between -1.5 and 0.5 metres considering the resistance to flood asphyxia of each riparian SPFT (Cerrillo et al., 2013). Da for terrestrials and transitional SPFTs were fixed as the limit immediately higher than $D_{e}$. The transpiration factors related to the water source, $r_{u}$ and $r_{s}$, ranged between 0.2 and 1.0, considering each riparian SPFT capabilities and preferences to transpire water from the unsaturated upper soil and/or from the saturated zone. For 
terrestrials $r_{s}$ was set null and $r_{u}$ was maximized. To characterize the rainfall water interception by the vegetation, values of Issc between 0.2 and $4.0 \mathrm{~mm}$ were analyzed for the different SPFTs, except for the pioneers that were considered to not intercept water.

The parameters that define the impacts module were set differently for each SPFT considering their resistance capacity to the specific impact under consideration. Globally, the parameters ranged within the following intervals: $\tau_{c}$ between 10 and $500 \mathrm{~N} \mathrm{~m}^{-2}$ (e.g. Benjankar et al., 2011; García-Arias et al., 2013), $\tau_{m}$ between 1 and $100 \mathrm{~N} \mathrm{~m}^{-2}, a_{c}$ and $w_{c}$ between 2 and 150 days and $a_{m}$ and $w_{m}$ between 1 and 50 days (Stevens and Waring, 1985; Kozlowski, 2002; Cerrillo et al., 2013), $u_{a}$ and $u_{w}$ between 0.1 and 0.9 .

The parameters that control the vegetation successional evolution were analyzed within wide ranges since no references were found to be representative for this study. In consequence, $B_{\min }$ ranged between $250 \mathrm{~g}$

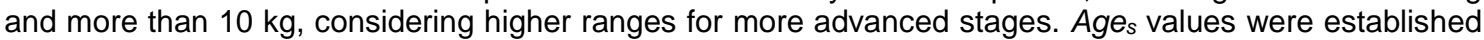
considering 1500 and 2550 days as boundaries for both $W_{\mathrm{CW}}$ and $\mathrm{W}_{\mathrm{TV}}$. Plant death caused by senescence was defined by values of Age $\max$ between almost a year and approximately three years for pioneers, between five and fourteen years for herbs and between a hundred and a hundred fifty years for adult cottonwood trees. Age $\tau$ and $T_{\min T V}$ were defined between 300 and 1450 days, and between 1500 and 4050 days, respectively (both considering a 30 days sampling interval).

The growth sub-module related parameters were set considering literature references and readjusted after preliminary simulations. Some values of the light extinction coefficient, $l_{e}$, of representative riparian species were found in Canell et al. (1987), Nagler et al. (2004) and Glenn et al. (2008). le finally ranged between 0.15 and 1.3. LUE range was common to every SPFT and was set between 0.5 and $2.5 \mathrm{gC} \mathrm{MJ} \mathrm{APAR}^{-1}$ (Canell et al., 1987; Turner et al., 2003). Both respiration rates and asymptotic maximum mortality rate were considered common for SPFTs within the same succession line. Values of $r r$ ranged between 0.001 and $0.010 \mathrm{gC} \mathrm{gN}^{-1} \mathrm{~d}^{-1}$ while $k_{a}$ ranged between $1.10^{-3}$ and $3.10^{-3}$ day $^{-1}$ (e.g. Sitch et al., 2003; Soeaert et al., 2004; Pasquato et al., 2014). Some values of SLA for specific terrestrial species were consulted in the TRY initiative on plant traits database and used as reference to set up the SLA ranges. Finally SLA ranged between 0.01 and $0.024 \mathrm{~m}^{2} \mathrm{gC}^{-1}$ for the reed series, between 0.008 and $0.014 \mathrm{~m}^{2} \mathrm{gC}^{-1}$ for the cottonwood series, and between 0.003 and $0.011 \mathrm{~m}^{2} \mathrm{gC}^{-1}$ for the terrestrial series.

Some additional parameters for evolution and competition processes were studied. These parameters were considered common for all the SPFTs. The $L A I_{\max }$ was set between 3.0 and $7.0 \mathrm{~m}^{2} \mathrm{~m}^{-2} ; Q i_{s r}$ ranged between 0.5 and $5.0 \mathrm{~m}^{3} \mathrm{~s}^{-1} ; T_{\text {gmax }}$ and $T_{\text {gmin }}$ ranges were established between 25 and $35^{\circ} \mathrm{C}$ and between 0 and $5{ }^{\circ} \mathrm{C}$, respectively; $H_{\text {gmin }}$, was considered to be limited between 10 and $60 \mathrm{~mm}$; PARh-e must be between 10 and $13 \mathrm{MJ} \mathrm{m}^{2} \mathrm{~d}^{-1}$; and NDE values ranged between 1 and 25 days.

Finally, the effective depth for bared soil water content evaporation $\left(D_{b s e}\right)$ that is a common parameter for every soil was varied between 0.1 and 0.5 metres for the model response analysis.

Table 1. RVDM model vegetation parameters and the boundaries considered for the model analysis

\begin{tabular}{|c|c|c|c|c|}
\hline Parameter name & Process & Units & $\begin{array}{l}\text { Minimum } \\
\text { bound }\end{array}$ & $\begin{array}{l}\text { Maximum } \\
\text { bound }\end{array}$ \\
\hline$a_{c}$, critical number of consecutive days under asphyxia stress & I & days & 2 & 150 \\
\hline$A g e_{\max }$, maximum plant longevity & $E$ & days & 300 & 5000 \\
\hline$A g e_{T}$, minimum age required for transition to mixed vegetation & C & days & 300 & 1450 \\
\hline$a_{m}$, minimum number of consecutive days under asphyxia stress & I & days & 1 & 50 \\
\hline$B_{\min }$, minimum biomass required to allow succession & $\mathrm{E}, \mathrm{C}$ & $g$ & 250 & 10.103 \\
\hline$D_{b s e}$, effective depth considered for evaporation from bare soil & WB & $\mathrm{m}$ & 0.1 & 0.5 \\
\hline$D_{e}$, effective root depth & WB & $\mathrm{m}$ & 0.05 & 3 \\
\hline$D_{r}$, maximum root depth & WB & $\mathrm{m}$ & 0.1 & 20 \\
\hline$H_{\text {gmin }}$, germination minimum capillary water content & $\mathrm{E}, \mathrm{C}$ & $\mathrm{mm}$ & 10 & 60 \\
\hline ISSC, specific storage capacity for rainfall interception & WB & $\mathrm{mm}$ & 0 & 0.4 \\
\hline$N D E$, number of days necessary for establishment & $\mathrm{E}, \mathrm{C}$ & days & 1 & 25 \\
\hline$P A R_{h-e}$, heliophyte-estiophyte photosynthesis active radiation & $\mathrm{E}$ & $M J m^{2} d^{-1}$ & 10 & 13 \\
\hline$Q_{i s r}$, maximum instantaneous spring flow to allow seed release & $E$ & $\mathrm{~m}^{3} \mathrm{~s}^{-1}$ & 0.5 & 5 \\
\hline$r r$, respiration rate & $E$ & $g C g^{-1} d^{-1}$ & 0.001 & 0.01 \\
\hline$r_{s}$, transpiration factor from the saturated zone & WB & dimensionless & 0 & 1 \\
\hline$r_{u}$, transpiration factor from the unsaturated zone & WB & dimensionless & 0 & 1 \\
\hline$S L A$, specific leaf area factor & $E$ & $\mathrm{~m} 2 \mathrm{gC}^{-1}$ & 0.003 & 0.024 \\
\hline$T_{\text {gmax }}$, germination critical maximum temperature & $\mathrm{E}, \mathrm{C}$ & ${ }^{\circ} \mathrm{C}$ & 25 & 35 \\
\hline$T_{\text {gmin }}$, germination critical minimum temperature & $\vec{E}, \mathrm{C}$ & ${ }^{\circ} \mathrm{C}$ & 0 & 5 \\
\hline$T_{\min T V}$, minimum time since mixed for transition to terrestrial & $\mathrm{C}$ & days & 1500 & 4050 \\
\hline$u_{a}$, relative minimum biomass under asphyxia stress & 1 & dimensionless & 0.1 & 0.9 \\
\hline$u_{w}$, relative minimum biomass under wilt stress & I & dimensionless & 0.1 & 0.9 \\
\hline
\end{tabular}




\begin{tabular}{llll}
\hline$\tau_{m}$, minimum shear stress & $\mathrm{I}$ & $\mathrm{N} \mathrm{m}^{-2}$ & 1 \\
$\Psi^{*}$, optimum pressure for plant transpiration & WB & $\mathrm{kPa}$ & 100 \\
$\Psi_{w p}$, wilting point pressure for plant transpiration & WB, I & $\mathrm{kPa}$ & 200 \\
\hline * Processes in which each parameter intervenes: C (competition module), E (evolution module), I (impacts module), WB (water balance module)
\end{tabular}

\section{Model performance evaluation}

The influence of the vegetation parameters values on the model response was analyzed through indices that have been reported by Mouton et al. (2010) as recommendable for species distribution comparison. By a cell-by-cell comparison of the SPFTs objective map and the one obtained after the simulation with the RVDM model, several confusion matrices were created. Considering the SPFTs, the main confusion matrix was created and taken as reference. A reclassification of the SPFTs on different phases (making a distinction between bare soil, pioneer, herb and woody types), on different lines (distinguishing reeds, cottonwoods, mixed and terrestrials) and considering only riparian, terrestrial and mixed vegetation, including this last the bare soil areas.

The confusion matrices that resulted from the cell by cell comparison between the observed and simulated maps allowed the calculation of the correctly classified instances $(\mathrm{CCl})$ and the kappa $(k)$ coefficient of agreement (Cohen, 1960). The model was considered correctly implemented when the objective functions obtained a satisfactory results $(\mathrm{CCl}>0.6$ and $k>0.5)$ for the calibration period. In addition, the vegetation dynamics was taken into account to select the parameters. Finally, good validation results $(C C />0.4$ and $k>0.3$ ) were considered desirable for the model to be correctly implemented.

\section{MODEL IMPLEMENTATION RESULTS}

The selected values for the vegetation parameters that define each SPFT are described in Table 2. In addition, PSC SPFTs were defined for the impact module with a $\tau_{c}$ value equal to $62 \mathrm{~N} \mathrm{~m}^{-2}$. The recruitment module was implemented with common values of some parameters for every SPFT: $Q i_{s r}=1.11 \mathrm{~m}^{3} \mathrm{~s}^{-1}$, $T_{\text {gmax }}=27^{\circ} \mathrm{C}, T_{\text {gmin }}=5^{\circ} \mathrm{C}, H_{\text {gmin }}=13 \mathrm{~mm}, P A R_{h-e}=12 \mathrm{MJ} \mathrm{m}^{2} \mathrm{~d}^{-1}$ and $N D E=17$ days. In addition, LAI $\max$ was considered to be limited to $5.6 \mathrm{~m}^{2} \mathrm{~m}^{-2}$ for the riparian ecosystem, $A g e_{T}=3300$ days, $T_{\min T V}=3600$ days. Finally, the $D_{b s e}$ soil parameter was calibrated as $0.31 \mathrm{~m}$.

Table 2. Set of selected vegetation parameters of RVDM for the Terde reach case study

\begin{tabular}{|c|c|c|c|c|c|c|c|c|c|}
\hline SPFT & $P_{R E}$ & Pcw & $\mathrm{P}_{\mathrm{TV}}$ & $\mathrm{H}_{\mathrm{RE}}$ & $\mathrm{Hcw}$ & $\mathrm{H}_{\mathrm{TV}}$ & $W_{c W}$ & $\mathrm{~W}_{\mathrm{MV}}$ & $\mathrm{W}_{\mathrm{TV}}$ \\
\hline$a_{c}$ (days) & 22 & 12 & 11 & 76 & 70 & 11 & 76 & 76 & 34 \\
\hline$A g e_{\max }$ (days) & 690 & 690 & 690 & 4340 & 3180 & 3950 & 36500 & - & - \\
\hline $\mathrm{Age}_{\mathrm{s}}$ (days) & - & - & - & - & - & - & 2250 & - & 2130 \\
\hline$a_{m}$ (days) & 6 & 6 & 6 & 46 & 23 & 10 & 43 & 43 & 17 \\
\hline$B_{\min }(\mathrm{g})$ & - & - & - & 250 & 2450 & 800 & 8500 & - & 6700 \\
\hline$C v()$ & 0.8 & 0.34 & 0.56 & 1 & 0.95 & 0.76 & 1 & 0.88 & 0.76 \\
\hline$D_{a}(\mathrm{~m})$ & 0.04 & 0.03 & 0.05 & -0.45 & -0.09 & 0.04 & -1.33 & -0.3 & 0.74 \\
\hline$D_{e}(\mathrm{~m})$ & 0.07 & 0.1 & 0.06 & 0.6 & 0.47 & 0.05 & 0.39 & 0.57 & 0.75 \\
\hline$D_{r}(\mathrm{~m})$ & 0.11 & 0.12 & 0.11 & 0.61 & 1.56 & 0.11 & 7.96 & 6.09 & 4.22 \\
\hline$I_{S S C}(\mathrm{~mm})$ & 0 & 0 & 0 & 1.49 & 2.1 & 2.37 & 3.85 & 3.88 & 3.92 \\
\hline$k_{a}\left(\right.$ day $\left.^{-1}\right)$ & 0.0012 & 0.0016 & 0.0016 & 0.0012 & 0.0016 & 0.0016 & 0.0016 & 0.0016 & 0.0016 \\
\hline$I_{e}()$ & 0.48 & 0.64 & 0.33 & 0.48 & 0.64 & 0.33 & 0.64 & 0.48 & 0.33 \\
\hline LUE (gC MJ APAR $\left.{ }^{-1}\right)$ & 2.21 & 1.61 & 1.39 & 2.21 & 1.61 & 1.39 & 1.61 & 1.5 & 1.39 \\
\hline$r r\left(g^{\prime} \mathrm{gN}^{-1} \mathrm{~d}^{-1}\right)$ & 0.003 & 0.002 & 0.003 & 0.003 & 0.002 & 0.003 & 0.002 & 0.003 & 0.003 \\
\hline$r_{s}()$ & 0.97 & 0.72 & 0 & 0.97 & 0.72 & 0 & 0.72 & 0.36 & 0 \\
\hline$r_{u}()$ & 0.14 & 0.26 & 1 & 0.14 & 0.26 & 1 & 0.26 & 0.63 & 1 \\
\hline$S L A\left(\mathrm{~m}^{2} \mathrm{gC}^{-1}\right)$ & 0.0137 & 0.011 & 0.0046 & 0.0137 & 0.011 & 0.0046 & 0.011 & 0.0078 & 0.0046 \\
\hline$u_{a}()$ & 0.68 & 0.66 & 0.48 & 0.68 & 0.66 & 0.48 & 0.66 & 0.57 & 0.48 \\
\hline$u_{w}()$ & 0.82 & 0.47 & 0.46 & 0.82 & 0.47 & 0.46 & 0.47 & 0.46 & 0.46 \\
\hline$w_{c}$ (days) & 11 & 14 & 25 & 21 & 39 & 65 & 47 & 47 & 111 \\
\hline$w_{m}$ (days) & 4 & 4 & 4 & 4 & 4 & 7 & 6 & 6 & 8 \\
\hline$\tau_{c}\left(\mathrm{~N} \mathrm{~m}^{-2}\right)$ & 107 & 138 & 71 & 220 & 250 & 75 & 441 & 441 & 258 \\
\hline$\tau_{m}\left(\mathrm{~N} \mathrm{~m}^{-2}\right)$ & 22 & 22 & 22 & 30 & 18 & 15 & 46 & 46 & 14 \\
\hline$\Psi^{*}(\mathrm{kPa})$ & 333 & 607 & 1050 & 333 & 607 & 1050 & 607 & 607 & 1050 \\
\hline$\Psi_{w p}(\mathrm{kPa})$ & 1835 & 2487 & 2538 & 1835 & 2487 & 2538 & 2487 & 2487 & 2538 \\
\hline
\end{tabular}

As can be seen in Table 3, the model performed satisfactorily in terms of objective functions values for every period analyzed. For the calibration period (2000-2006) $C C l=0.67$ and $k=0.59$ values were obtained in terms of SPFTs distribution prediction. The results for the objective functions were similar when other simplified plant classifications (phases, lines and riparian-terrestrial-mixed vegetation) were considered. In particular, the calibration period obtained $C C l=0.76(k=0.48)$ for the phases classification, $C C l=0.72$ $(k=0.60)$ for the lines classification and $C C l=0.80(k=0.68)$ for the riparian, mixed and terrestrial vegetation distinction. The validation results were additionally comparable with values of $\mathrm{CCl}$ that ranged between 0.50 and 0.64 , and with values of $k$ up to 0.55 in the prediction of the SPFTs distribution. Considering the results, the model has shown to perform slightly better in the classification of phases than in the 
differentiation of different succession lines. However, all the statistics revealed the capabilities of the model for simulating the relevance of the different SPFTs in the reach plant communities.

Table 3. Objective functions results for the model performance evaluation on the calibration and validation periods ( $\mathrm{CCl}$ corresponds to the correctly classified instances and $k$ is the kappa coefficient of agreement)

\begin{tabular}{|c|c|c|c|c|c|c|}
\hline & \multirow{2}{*}{ Time period } & \multirow{2}{*}{$\begin{array}{l}\text { Objective } \\
\text { function }\end{array}$} & \multicolumn{4}{|c|}{ State variable } \\
\hline & & & SPFTs & Phases & Lines & $\mathrm{RI}-\mathrm{TV}$ \\
\hline \multirow{2}{*}{ Calibration } & \multirow{2}{*}{$2000-2006$} & $\mathrm{CCl}$ & 0.670 & 0.764 & 0.715 & 0.795 \\
\hline & & $k$ & 0.589 & 0.479 & 0.601 & 0.679 \\
\hline \multirow{4}{*}{ Validation } & \multirow{2}{*}{$2006-2009$} & $\mathrm{CCl}$ & 0.639 & 0.772 & 0.666 & 0.755 \\
\hline & & $k$ & 0.545 & 0.454 & 0.535 & 0.622 \\
\hline & \multirow{2}{*}{$2000-2009$} & $\mathrm{CCl}$ & 0.501 & 0.643 & 0.549 & 0.665 \\
\hline & & $k$ & 0.383 & 0.233 & 0.368 & 0.489 \\
\hline
\end{tabular}

In addition, the results showed the model to be potentially able to represent the spatial distribution of these SPFTs. The distinction between the terrestrial vegetation and the riparian SPFTs was excellent. The model is capable to prevent the simulation of terrestrials SPFTs in pixels typically riparian (areas located near the aquatic zone with high capillary water content in the upper soil and considerably shallow water table). In the same vein, the most demanding riparian plant types as reeds, were not simulated in pixels typically terrestrial (dry areas far from the aquatic zone where the water table is not accessible). Even for less demanding plant types, the transverse distribution of the vegetation was correctly represented by RVDM for every period analyzed (Figure 5, Figure 6). The main difficulty found by the model was on the establishment of the main gravel bar observed in the reach. Better representation of bare soil pixels was observed for the validation periods that included flood events (Figure 6).

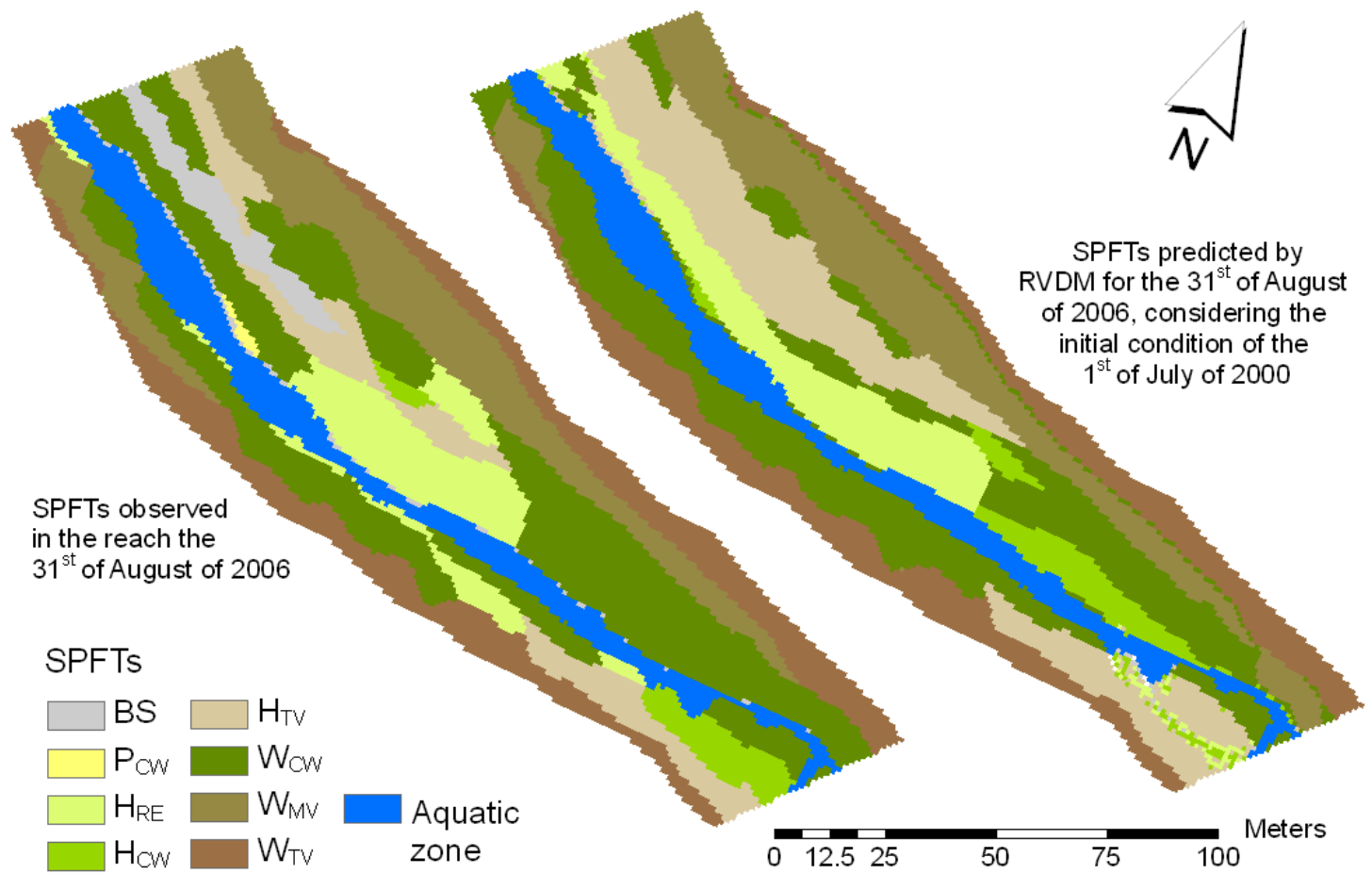

Figure 5. RVDM simulated vegetation distribution compared to the observed vegetation in 2006 for the considered SPFTs (simulated period 2000-2006). 


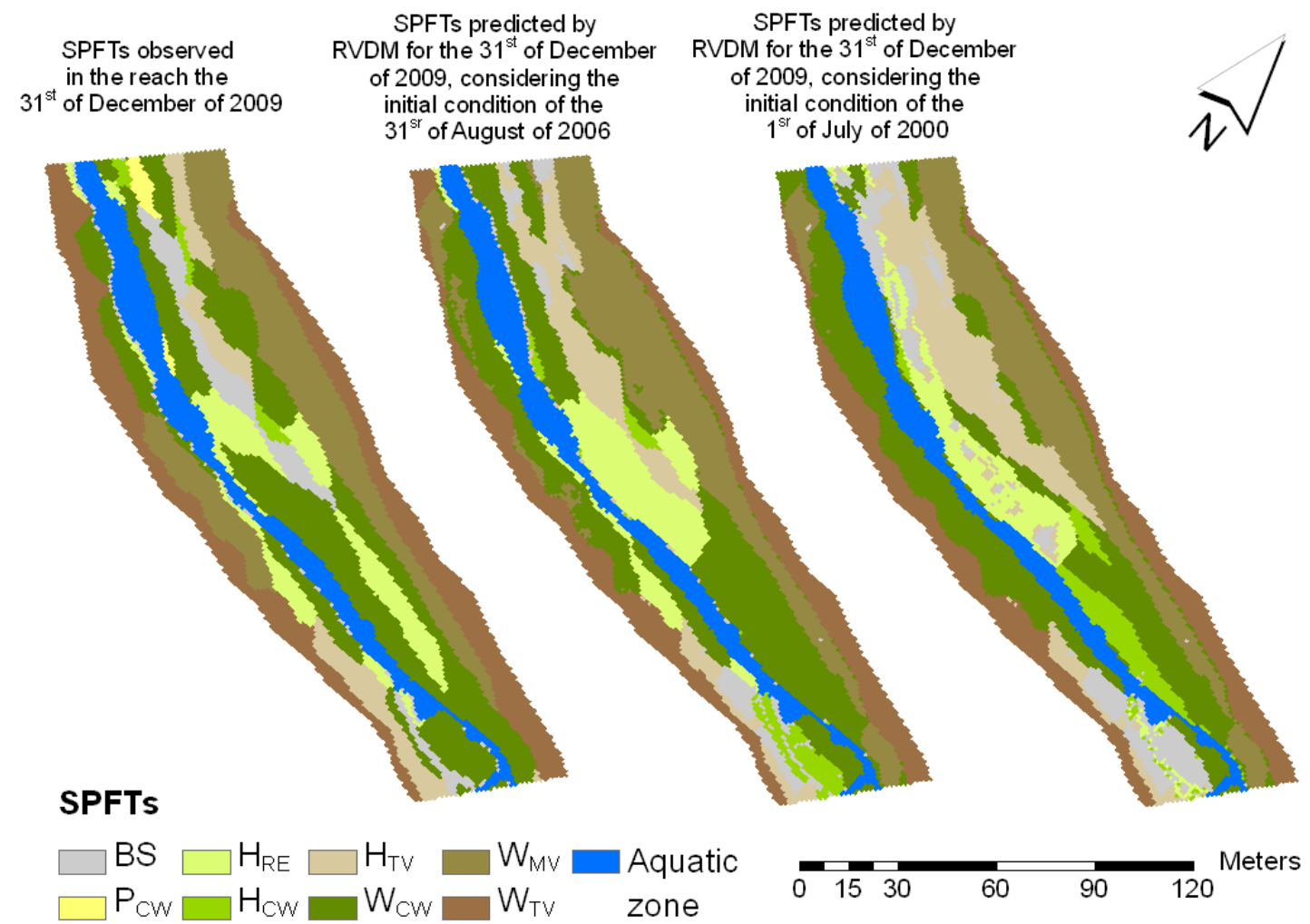

Figure 6. RVDM simulated vegetation distribution compared to the observed vegetation in 2009 for the considered SPFTs (simulated periods 2006-2009 and 2000-2009).

Biomass loss analyses indicated that RVDM can contribute with complementary information to the changes of the vegetation distribution under a destructive flood. The flood occurred the $11^{\text {th }}$ of September of 2006 registered a $342 \mathrm{~m} / \mathrm{s}$ peak flow. Despite the minor changes observed in the vegetation distribution, most of the reach area suffered the impact of the water shear stress in terms of biomass loss (Figure 7). Most floodplain areas were affected slightly and the biomass loss estimated by the model was lower than the $10 \%$. Many cottonwood areas lowered their biomass to the $70-90 \%$. Some critical pixels suffered a reduction of more than the $60 \%$, leading to biomass remains between the $20 \%$ and the $40 \%$, but the complete removal of these cottonwoods was very rare. As expected, the terrestrial herbs resulted to be very vulnerable under this situation and the damaged pixels resulted in complete plant removal in most of the cases. The reeds withstood the flood in the most critical zones of the reach. In fact, they were completely removed only in a few pixels and endured the peak flow with little biomass loss, lower than the $20 \%$. 


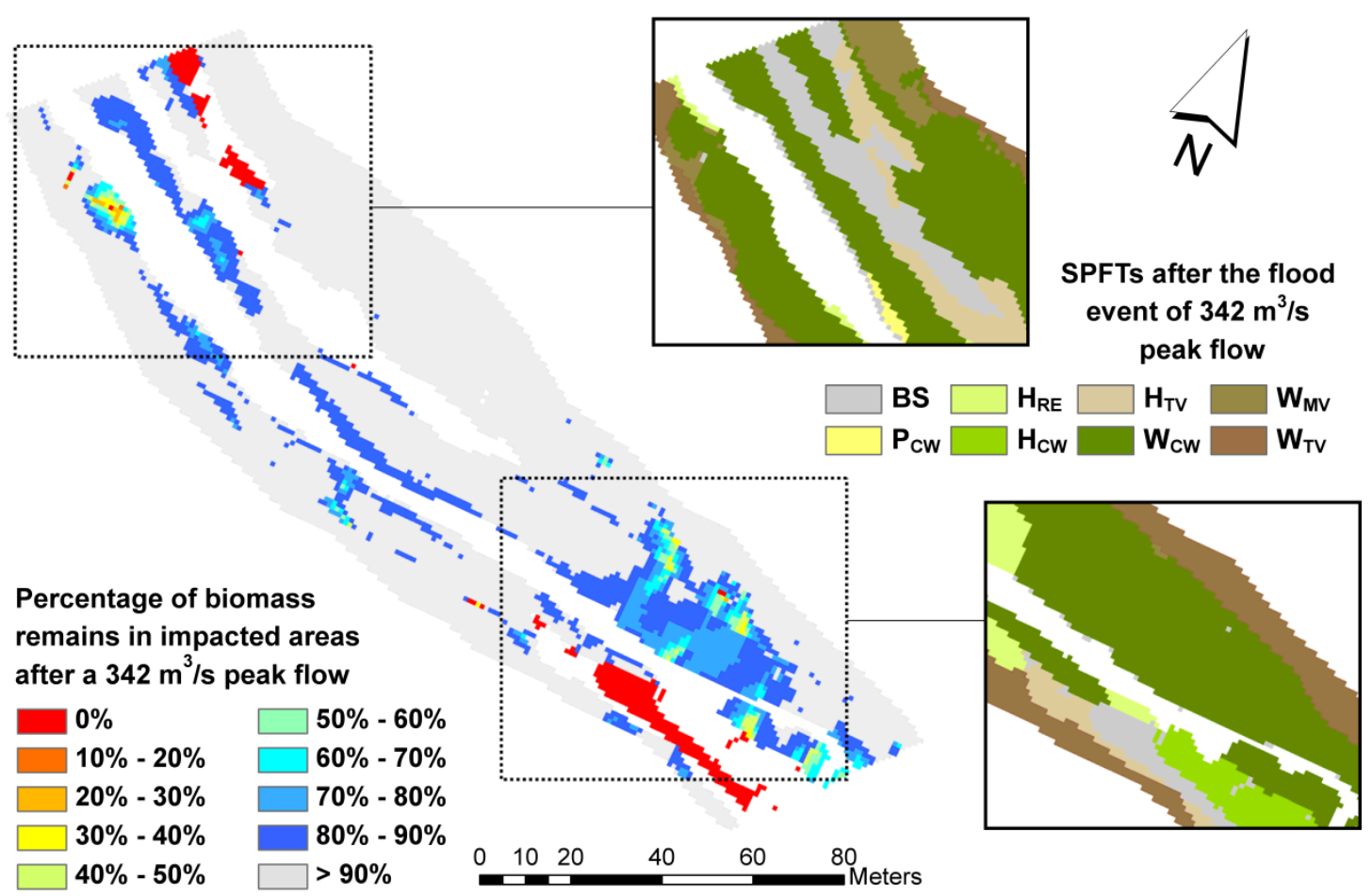

Figure 7. RVDM simulated vegetation distribution and percentage of biomass remains after a flood event of $342 \mathrm{~m}^{3} / \mathrm{s}$ peak flow.

\section{MODEL GENERAL SENSITIVITY ANALYSIS}

A general sensitivity analysis (GSA) (Hornberger and Spear, 1980) was performed on the model to identify the role, understood as degree of influence, of the different parameters on the model performance. In particular, we were especially interested in the influence of all vegetation parameters and the soil parameter $D_{b s e}$. Following the Monte Carlo approach, the parameter values were randomly sampled from uniform distributions within the ranges defined in Table 1. Two hundred and fifty thousand independent sets of parameters were analyzed with the RVDM. The performance was evaluated using the SPFTs maps of the $31^{\text {st }}$ of August of 2006 and $31^{\text {st }}$ of December of 2009, considering the initial condition of the $1^{\text {st }}$ of July of 2000. $\mathrm{CCl}$ and $k$ objective functions were calculated for both model results. In consequence, four criteria (CClO6, k06, CClO9 and k09) were analyzed to divide the sets of parameters in two groups: behavioural and non-behavioural. Simulation results were considered satisfactory when $\mathrm{CCl}$ and $k$ values were higher than established thresholds. The sets of parameters that led to these satisfactory results were regarded as belonging to the behavioural group. On the contrary, the sets of parameters that produced unsatisfactory results were led to the non-behavioural group. Then, the cumulative probability distributions of each parameter within the two groups were obtained and, through the Kolmogorov-Smirnov two-sample test (KS), the relative importance of each parameter's contribution to the model simulation was evaluated. The KS statistic $\left(K S_{s t a t}\right)$ is the maximum absolute difference between the cumulative distribution function calculated from the behavioural sets of parameters and the the cumulative distribution function calculated from the non-behavioural sets of parameters. Higher values of the $K S_{\text {stat }}$ represent a greater maximum distance in terms of probability between the cumulative probability distributions of the behavioural and nonbehavioural values for a specific parameter. In consequence, the higher is the $K S_{\text {stat, }}$ the more influential on the model performance is the parameter. For more details in other practical cases see for example Wade et al. (2001), Medici et al. (2012) or Pasquato et al. (2014).

The selection of $\mathrm{CCl}$ and $k$ thresholds for the separation of the two groups, behavioural and nonbehavioural, is not an easy task. The use of relaxed $\mathrm{CCl}$ and $\mathrm{k}$ thresholds led to a high number of parameters sets considered behavioural. The identification of influent parameters was difficult, since the cumulative probability distributions of the two groups, did not show sufficient differences. In consequence, the sensitivity to parameters important for the model performance was distorted. On the contrary, very tough $\mathrm{CCl}$ and $k$ thresholds led to a very low number of behavioural simulations that resulted in a high number of influent parameters. Finally, $\mathrm{CCl}$ and $\mathrm{k}$ thresholds were adjusted taking into account the model capabilities and the proportion between the number of behavioural and non-behavioural sets of parameters. These thresholds were the highest that allowed the greatest number of behavioural parameters sets to be 
kept, whilst the parameter sensitivity ranking remained unchanged. In particular, $\mathrm{CCl}$ and $k$ values of 0.4 were considered optimal for every vegetation classifications except the classification in phases that required a $k$ threshold reduction to 0.3 . This approach resulted in the identification of a representative number of influent parameters. However, depending on the classification of the vegetation under study, the relative importance between the influent parameters changed. The SPFTs classification was mostly influenced by the parameter that represents the minimum time required for the mixed vegetation to start the transition to the terrestrial vegetation, $T_{\min T V}\left(K S_{s t a t}=0.43\right)$, followed by transpiration factors, $r_{u}$ and $r_{s}$ $\left(K S_{\text {stat }}\right.$ up to 0.33$)$, critical shear stress of early stages, $\tau_{c} P S C\left(K S_{\text {stat }}\right.$ up to 0.31$)$, root depths, $D_{r}, D_{e}$ and $D_{a}$ $\left(K S_{\text {stat }}\right.$ up to 0.31$)$ and minimum biomass required to allow succession, $B_{\min }\left(K S_{\text {stat }}\right.$ up to 0.15$)$. Other parameters as pressures for plant transpiration, germination minimum capillary water content in the upper soil and critical number of consecutive days under wilt stress resulted on different cumulative probability distributions of the behavioural and the non-behavioural groups. However, the differences were substantially lower and the $K S_{\text {stat }}$ values remained under 0.08 . Figure 8 illustrates the cumulative probability distributions of the behavioural and the non-behavioural values for these parameters.
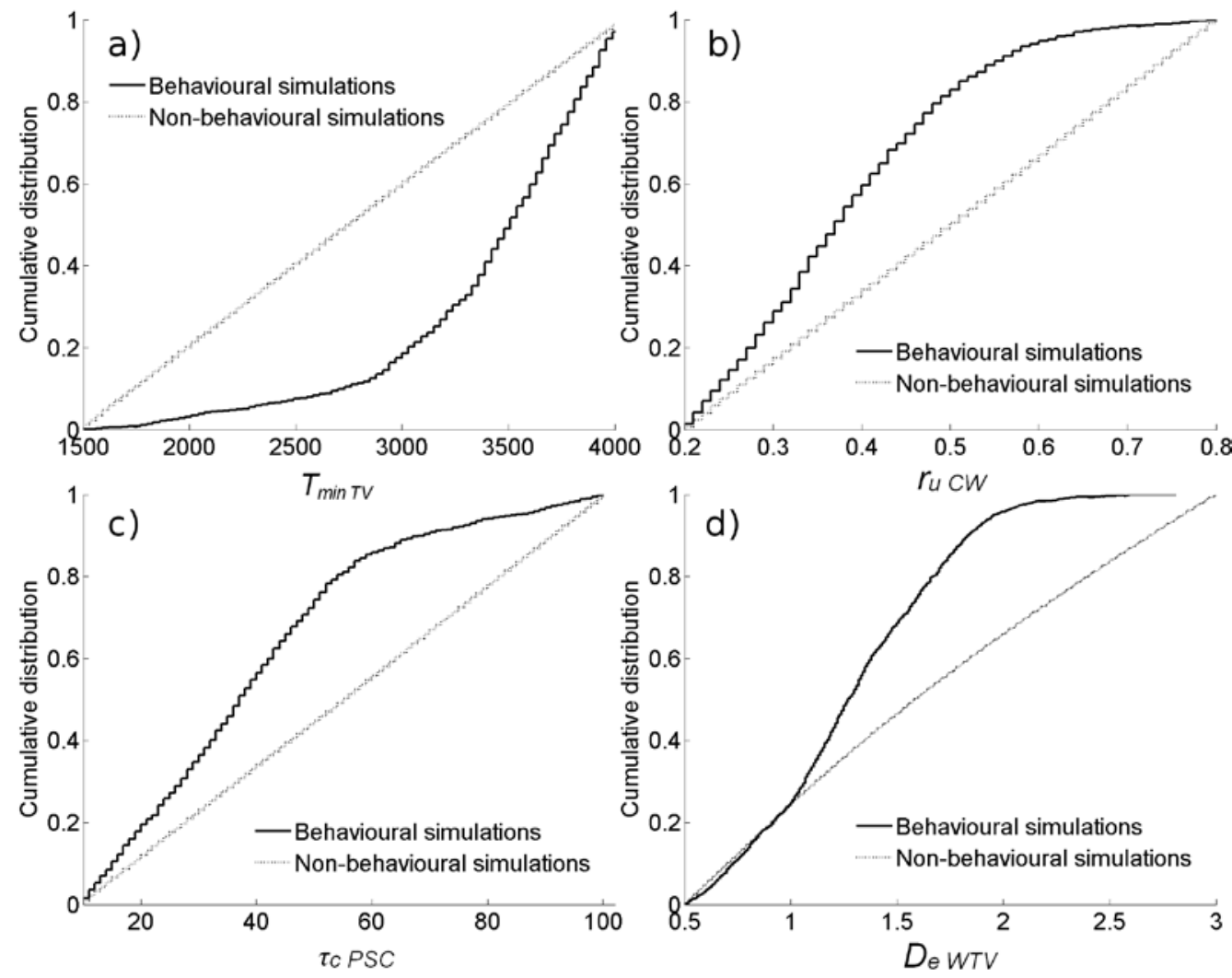

Figure 8. Cumulative probability distributions of the behavioural and non-behavioural values considered for the most influent parameters: a) $T_{\min T V}$, b) $\left.r_{u} \mathrm{CW}, \mathrm{c}\right) \tau_{c}$ PSC, d) $D_{\mathrm{e}} W T V$

The key model parameters for the vegetation phases classification results were root depths, $D_{r}, D_{e}$ and $D_{a}$ $\left(\mathrm{KS}_{\text {stat }}\right.$ up to 0.45 ), followed by minimum biomass required to allow succession, $B_{\min }\left(\mathrm{KS}_{\text {stat }}\right.$ up to 0.43 ), the germination minimum capillary water content in the upper soil, $H_{\text {gmin }}\left(K_{\text {stat }}=0.14\right)$ and the effective depth considered for evaporation from bare soil, $D_{b s e}\left(K_{s} s_{\text {stat }}=0.13\right)$. As it was expected, the minimum time since mixed for transition to terrestrial parameter $\left(T_{\min T V}\right)$ resulted to be not influential at all under this classification. In addition, critical shear stresses $\left(\tau_{c}\right)$ and transpiration factors $\left(r_{u}\right.$ and $\left.r_{s}\right)$ resulted to have influence on the model results but less than when SPFTs classification is pursued. When the vegetation lines classification was considered, the results were comparable to those obtained under the SPFTs classification. However, coverage of pioneers, $C V_{P}\left(K S_{\text {stat }}\right.$ up to 0.26$)$, and germination minimum capillary water content in the upper soil, $H_{\text {gmin }}\left(\mathrm{KS}_{\text {stat }}=0.20\right)$, resulted to be more influential than root depths, $D_{r}, D_{e}$ and $D_{a}\left(\mathrm{KS}\right.$ stat lower than 0.13), and critical shear stress of early stages, $\tau_{c}$ PSC (KS stat lower than 0.10).

The same occurred for the simplest riparian-terrestrial-mixed vegetation classification, that is mostly influenced by the coverage of pioneers, $C V_{P}\left(K S_{\text {stat }}\right.$ up to 0.29$)$, followed by the minimum time since mixed for transition to terrestrial parameter, $T_{\min T V}\left(\mathrm{KS}_{\mathrm{stat}}=0.28\right)$, and the germination minimum capillary water content in the upper soil, $H_{\text {gmin }}\left(K_{\text {stat }}=0.27\right)$. In addition transpiration factors, $D_{b s e}$, minimum biomass required to allow succession and root depths have to be considered carefully when this classification is pursued. 


\section{DISCUSSION AND CONCLUSIONS}

RVDM is an ecohydrological model that can represent a major improvement on the vegetation dynamics modelling in riparian areas of semi-arid environments. The vegetation development is assumed to depend on the functional relationship between the river hydrology, the physical processes that take place in the riparian areas and the vegetation communities that may occupy these areas. Important advantages of RVDM include: higher temporal resolution (daily time step) than previous similar models, new plant classification approach useful for research and management (the concept of SPFTs), easy implementation with excellent results as shown in the presented case study, good representation of the processes that determine the vegetation dynamics in riparian areas (impacts, evolution and competition processes) and feasible inclusion of river morphodynamics in the simulations (different Digital Elevation Models and soil maps can be given to the model as inputs during simulation), which has been pointed out as a main lack of previous models (Camporeale et al., 2013).

The SPFTs approach as the main vegetation state variable combines the advantages of two previous plant classification approaches that have demonstrated to be useful in riparian areas: functional types (e.g. García-Arias et al., 2014) and phases of succession (e.g. Benjankar et al., 2011). Following the functional types classification approach, the different SPFTs include plants that respond similarly to environmental factors and have similar effects on the dominant processes of the ecosystem (Woodward and Wolfgang, 1996). The analysis of some limiting hydrological and morphological processes that affect the vegetation dynamic evolution is possible by including the succession concept. In consequence, RVDM considers each proposed functional type as a phase of a succession line on its SPFTs classification. Of course the SPFTs can be a posteriori grouped into phases or lines if successional patterns analyses are pursued or they can be grouped into riparian, terrestrial and mixed plant functional types if the analyses of the functional relations with the ecosystem are under study.

Despite the differences observed in the general sensitivity analysis of the model considering different plant classification methods, eight most influential parameters were identified. These parameters are: minimum time since mixed for transition to terrestrial, root depths, transpiration factors, critical shear stress of early stages, minimum biomass required to allow succession, germination minimum capillary water content in the upper soil, effective depth considered for evaporation from bare soil and coverage of pioneers. While the parameters considered not influential obtained $K S_{\text {stat }}$ values lower than 0.07 , the influential parameters resulted on $K S_{\text {stat }}$ values between 0.10 and 0.45 and showed important differences between the cumulative probability distributions of the behavioural and the non-behavioural groups. In consequence, their values adjustment must be carefully taken into account in the model implementation.

Classical information of the river reach meteorology, hydrology, and geomorphology can be easily adapted to obtain the necessary inputs to implement RVDM. If needed as initial condition and/or for calibration or validation, SPFTs maps can be obtained from aerial photographs and, in turn, the biomass maps can be estimated by means of different SPFT-biomass definitions. In consequence, the implementation of the model can be qualified as easy and intuitive, which makes RVDM manageable not only for researches, but also for water managers and stake-holders. The model calibration and validation have obtained performance results comparable, or even better, to the most recent pre-existent models (e.g. Benjankar et al., 2011; García-Arias et al., 2013; Ye et al., 2013; García-Arias et al., 2014). Considering the SPFTs classification, the model obtained $\mathrm{CCl}$ values of 0.67 for calibration and between 0.5 and 0.64 for validation. The results of the kappa coefficient of agreement, approximately between 0.4 and 0.6 demonstrated the good model performance once the agreements by chance are dismissed. It has to be considered that the kappa coefficient is a very conservative measure of agreement. In addition, a highly detailed classification results by differencing between SPFTs. When more relaxed classifications are adopted, the model improves its performance. For example, the phases, lines and riparian-terrestrialmixed classifications improved the results of $\mathrm{CCl}$ until values between 0.7 and 0.8 for the calibration period. The results for the validation periods under these simplified plant classification were also comparable with kappa values up to 0.52 and $\mathrm{CCl}$ values between 0.55 and 0.77 .

The RVDM model allows focusing the attention to specific zones of the reach, to specific ecohydrological variables, and to specific timing. For example, the effect of a destructive flow can be analyzed not only in changes of the vegetation distribution but also in terms of biomass loss. The riparian vegetation is commonly adapted to hydrological disturbances. In consequence, changes in the vegetation distribution are frequently not observed in most of the pixels. The estimations of the impacts over the biomass allow the determination of damaged zones. After analyzing a $342 \mathrm{~m}^{3} / \mathrm{s}$ peak flow in the case study, the results showed that the pixels occupied by terrestrials that were located near the stream were completely devastated in most of the cases. On the contrary, less than the $30 \%$ of the cottonwood biomass was removed in most of the impacted areas and the complete removal of this succession line was very rare. Even the reeds that are in the most critical zones of the reach are completely removed only exceptionally. The results showed that biomass losses lower than $10 \%$ are possible in reed zones for this flood magnitude although the vegetation distribution does not change.

The representation of determinant processes for the vegetation dynamics has been carefully studied in this research in order to include the main state variables and most influent parameters. For example, recent studies put forward excessively simplistic approaches for the plant recruitment establishment based on the elevation over the base flow level (Mahoney and Rood, 1998; Benjankar et al., 2011; García-Arias et al., 2013; Benjankar et al., 2014). Benjankar et al. (2014) have introduced additional dependencies of the 
successful cottonwood recruitment on the peak flow timing and shear stress and a mortality rate. However, germination is a complex process that is mainly controlled by temperature, moisture, oxygen and light (Raven et al., 2012) and little attention has been paid to these important environmental variables in previous approaches. An advanced spatially distributed recruitment conceptualization is presented within RVDM in this paper. This conceptualization, presented as a RVDM sub-model, defines successively the three main stages of the plant recruitment: seeds presence, seeds germination and seedlings establishment. Its parameterization includes thresholds for determinant environmental and hydrological variables that define not only if there is a successful recruitment but also which succession line succeeds. The approach proposed in RVDM bases the competition between riparian lines on the light conditions and between riparian and terrestrials on the transpiration capabilities under the specific hydrological conditions at each cell.

In other previous papers, the biomass growth in riparian areas has been considered as function of the distance from the river bank, specifically influenced by the accessibility to the water table and the flood disturbances (Perucca et al., 2006; Ye et al., 2013). Biomass growth in RVDM is established by a light use efficiency model made up of a logistic component that defines the normal growth under favourable conditions and a moisture stress component that defines the retarded growth. This approach has provided good results before for hillsides vegetation growth modelling in semi-arid environments (e.g. Montaldo et al., 2005, Pasquato et al., 2014). In this paper, it is demonstrated through the case study implementation that a process based model that considers light and water availability as main drivers for plant growth in riparian semi-arid areas, provides better results than less complex approaches that limits the vegetation evolution to plant age (Benjankar et al., 2011; García-Arias et al., 2013). Previous studies frequently fix the biomass loss to constant decreasing rates (e.g. Ye et al., 2013) when a critical stress threshold is exceeded. Other models leave on side the biomass loss estimations and consider the critical stress threshold to cause plant death and complete disappearance (e.g. Benjankar et al., 2011; García-Arias et al., 2013). In RVDM, the biomass loss caused by shear and moisture stresses is established in the impacts module by means of linear loss functions defined by minimum and critical values of the variables that represent each stress. In consequence, the decreasing rate is variable and depends on the stress intensity, which has been considered more appropriate.

Competition is not considered to limit the biomass growth or loss between competitors in RVDM. When competition occurs, it is analyzed at each time step through an internal parallel counting. Until the competition variables define a vegetation change, RVDM gives preference to the pre-existing vegetation type. In consequence, competition is "won" when there is a competitor stronger than the other, but the vegetation does not suffer changes when the strength or weakness is the same for the competitors. The natural transition from the riparian communities to the terrestrial ecosystem, when river disturbances do not occur, is modelled in RVDM by means of a transitional SPFT of mixed vegetation. This approach allows considering a buffer area that can evolve to either the riparian or the terrestrial vegetation. The water accessibility and the transpiration capabilities of each vegetation types make the difference in terms of resource competency. As a result, the absence of hydrological disturbances is not enough to allow the riparian replacement by terrestrials; it is necessary for the terrestrials to be capable to perform better than riparian. This better performance is analyzed in RVDM by comparing riparian and terrestrial evapotranspiration indices under the same environmental and hydrological conditions. If these conditions are not advantageous for the terrestrials to occupy the area, the riparian ages and finally dies and a new competency is analyzed in the recruitment of the non-vegetated area.

Considering that Ye et al. (2013) demonstrated that statistical models are not able to respond robustly under different flow regimes and complex flow patterns, and that the RVDM model improves previous process-based models in many ways, its complexity is justified. In addition, although 36 parameters are included in the model conceptualization, the global sensitivity analysis demonstrated that only 8 types of parameters are actually influent. This fact allows the consideration of RVDM as a manageable and a useful tool for riparian vegetation dynamics analyses in different case studies.

In summary, the model conceptualization, the methodology adopted for the model analysis and implementation, and the obtained results in the presented case study are sufficient to consider this paper a satisfactory first basic step. Further research is intended to pursue the river morphodynamics inclusion in the model implementation, its implementation in additional semi-arid river reaches and some analyses of the model performance under other climate conditions. Currently, the model is being used for global change scenarios analyses and it is being tested if it is a useful tool for the determination of environmental flows. As main conclusion, RVDM can be considered an innovative and a useful tool to provide a better understanding of the plant communities dynamics under the ecohydrological processes that take place in riparian areas.

Finally, the source code of RVDM is written in FORTRAN and can be obtained from the first author (algarar2@upv.es) upon request.

\section{ACKNOWLEDGEMENTS}

This research has been developed within the research project SCARCE (Consolider-Ingenio 2010 CSD2009-00065) supported by the Spanish Ministry of Economy and Competitiveness. The hydrological data, the aerial photographs and the meteorological data have been supplied by the Hydrological Studies 
Centre (CEH-CEDEX), the Jucar River Basin Authority and the Spanish National Meteorological Agency (AEMET), respectively.

Some data provided by the TRY initiative on plant traits (http://www.trydb.org) have been consulted for reference. The TRY initiative and database is hosted, developed and maintained by J.Kattge and G. Bönisch (Max-Planck-Institute for Biogeochemistry, Jena, Germany).

\section{REFERENCES}

Baird KJ, Maddock III T. 2005. Simulating riparian evapotranspiration: a new methodology and appli cation for groundwater models. Journal of Hydrology 312: 176-190. DOI: 10.1016/j.jhydrol.2 005.02.014.

Benjankar R, Egger G, Jorde K, Goodwin P, Glenn NF. 2011. Dynamic floodplain vegetation model development for the Kootenai River, USA. Journal of Environmental Management 92(2011): 3058-3070. DOI: 10.1016/j.jenvman.2011.07.017.

Benjankar R, Burke M, Yager E, Tonina D, Egger G, Rood SB, Merz N. 2014. Development of a S patially-distributed hydroecological model to simulate cottonwood seedling recruitment along rivers. Journal of Environmental Management, 145(2014):277-88. DOI: 10.1016/j.jenvman.2 014.06.027.

Boedeltje G, Bakker JP, Ten Brinke A, Van Groenendael JM, Soesbergen M. 2004. Dispersal pheno logy of hydrochorous plants in relation to discharge, seed release time and buoyancy of $\mathrm{s}$ eeds: the flood pulse concept supported. Journal of Ecology 92: 786-796. DOI: 10.1111/j.0 022-0477.2004.00906.x

Brinson MM, Verhoeven J. 1999. Riparian forests. In: Hunter, M.L. 1999. Maintaining biodiversity in forest ecosystems. NY, USA, Cambridge University Press. P. 265-299.

Campbell GS. 1974. A simple method for determining unsaturated conductivity from moisture retenti on data. Soil Science, 117(6): 311.

Camporeale C, Ridolfi L. 2006. Riparian vegetation distribution induced by river flow variability: A st ochastic approach, Water Resources Research 42: W10415, DOI:10.1029/2006WR004933.

Camporeale, C, Perucca E, Ridolfi L, Gurnell AM. 2013. Modeling the interactions between river mo rphodynamics and riparian vegetation, Reviews of Geophysics 51: 379-414. DOI: 10.1002/r og.20014.

Canadell J, Jackson RB, Ehleringer JB, Mooney HA, Sala OE, Schulze ED. 1996. Maximum rootin $\mathrm{g}$ depth of vegetation types at the global scale. Oecologia 108(4):583-595. DOI: 10.1007/B F00329030

Canell MGR, Milne R, Sheppard LJ, Unsworth MH. 1987. Radiation interception and productivity of willow. Journal of Applied Ecology 24: 261-278.

Cao X, Jia JB, Li H, Li MC, Luo J, Liang ZS, Liu TX, Liu WG, Peng CH, Luo ZB. 2012. Photosyn thesis, water use efficiency and stable carbon isotope composition are associated with ana tomical properties of leaf and xylem in six poplar species. Plant Biology 14: 612-620. DOI: 10.1111/j.1438-8677.2011.00531.x

Cerrillo T, Rodriguez ME, Achinelli F, Doffo G, Luquez VMC. 2013. Do greenhouse experiments pr edict willow responses to long term flooding events in the field? Bosque 34(1): 71-79. D OI: $10.4067 / S 0717-92002013000100009$

Cohen J. 1960. A coefficient of agreement for nominal scales. Educational and psychological measu rement 20(1): 37-46. DOI: 10.1177/001316446002000104

Collalti A, Perugini L, Santini M, Chiti T, Nolè A, Matteucci G, Valentini R. 2014. A process-based model to simulate growth in forests with complex structure: Evaluation and use of 3D-CM CC Forest Ecosystem Model in a deciduous forest in Central Italy. Ecological Modelling 27 2: 362-378. DOI: 10.1016/j.ecolmodel.2013.09.016

Corenblit, D, Tabacchi E, Steiger J, Gurnell A. 2007. Reciprocal interactions and adjustments betwe en fluvial landforms and vegetation dynamics: A review of complementary approaches. Ear th Science Reviews 84: 56-86. DOI: 10.1016/j.earscirev.2007.05.004

Corenblit D, Steiger J, Tabacchi E, González E, Planty-Tabacchi AM. 2014. Ecosystem engineers m odulate exotic invasions in riparian plant communities by modifying hydrogeomorphic conne ctivity. River Research and Applications 30: 45-59. DOI: 10.1002/rra.2618

Coulthard, TJ, Hicks DM, Van De Wiel MJ. 2007. Cellular modelling of river catchments and reache s: Advantages, limitations and prospects. Geomorphology 90(3-4): 192 - 207.

Douma JC, de Haan MWA, Aerts R, Witte JPM, van Bodegom PM. 2012. Succession-induced trait shifts across a wide range of NW European ecosystems are driven by light and modulate d by initial abiotic conditions. Journal of Ecology 100: 366-380. DOI: 10.1111/j.1365-2745.2 011.01932.x

Formann E, Habersack HM, Schober St. 2007. Morphodynamic river processes and techniques for assessment of channel evolution in Alpine gravel bed rivers. Geomorphology 90: 340-355. DOI: 10.1016/j.geomorph.2006.10.029.

García-Arias A, Francés F, Ferreira T, Egger G, Martínez-Capel F, Garófano-Gómez V, Andrés-Dom énech I, Politti E, Rivaes R, Rodríguez-González P. 2013. Implementing a dynamic riparia 
$\mathrm{n}$ vegetation model in three European river systems. Ecohydrology 6: 635-651. DOI: 10.10 02/eco.1331

García-Arias A., Francés F., Morales-de la Cruz M., Real J., Vallés-Morán F., Martínez-Capel F., Ga rófano-Gómez V. 2014. Riparian evapotranspiration modelling: model description and imple mentation for predicting vegetation spatial distribution in semi-arid environments. Ecohydrol ogy, 7:659-677. DOI: 10.1002/eco.1387

Glenn EP, Huete AR, Nagler P, Nelson SG. 2008. Relationship Between Remotely-sensed Vegetatio n Indices, Canopy Attributes and Plant Physiological Processes: What Vegetation Indices Can and Cannot Tell Us About the Landscape. Sensors 2008, 8, 2136-2160. ISSN: 14248220

González E, Comín FA, Muller E. 2010. Seed dispersal, germination and early seedling establishme nt of Populus alba L. under simulated water table declines in different substrates. Trees 2 4:151-163. DOI 10.1007/s00468-009-0388-y

Greet J, Webb JA, Cousens RD. 2011. The importance of seasonal flow timing for riparian vegetati on dynamics: A systematic review using causal criteria analysis, Freshwater Biology 56 (7) : 1231-1247. DOI: 10.1111/j.1365-2427.2011.02564.x

Guilloy-Froget H, Muller E, Barsoum N, Hughes FMM. 2002. Dispersal, germination, and survival of Populus Nigra L. (Salicaceae) in changing hydrologic conditions. Wetlands 22(3): 478-488 . DOI: 10.1672/0277-5212(2002)022[0478:DGASOP]2.0.CO;2

Gurnell A, Thompson K, Goodson J, Moggridge H. 2008. Propagule deposition along river margins: Linking hydrology and ecology, Journal of Ecology 96(3): 553-565. DOI: 10.1111/j.1365-274 5.2008.01358.x

Guymon GL. 1994. Unsaturated zone hydrology. Prentice Hall, U.S.A. 210 p.

Hood WG, Naiman RJ. 2000. Vulnerability of riparian zones to invasion by exotic vascular plants. $P$ lant Ecology 148: 105-114. DOI: 10.1023/A:1009800327334

Hooke JM, Brookes CJ, Duane W, Mant JM. 2005. A simulation model of morphological, vegetation and sediment changes in ephemeral streams. Earth Surface Processes and Landforms 3 0(7): 845-866. DOI: 10.1002/esp.1195.

Hornberger GM, Spear RC. 1980, Eutrophication in Peel Inlet-l. The problem-defining behavior and a mathematical model for the phosphorus scenario, Water Research, 14(1), 29-42, doi:10 .1016/0043-1354(80)90039-1.

Kozlowski TT. 2002. Physiological-Ecological impacts if flooding on riparian forest ecosystems. Wetla nds 22(3): 550-561. DOI: 10.1672/0277-5212(2002)022[0550:PEIOFO]2.0.CO;2

Laio F, Porporato A, Ridolfi L, Rodríguez-Iturbe I. 2001. Plants in water-controlled ecosystems: activ e role in hydrologic processes and response to water stress; II Probabilistic soil moisture dynamics. Advances in Water Resources 24: 707-723. DOI: 10.1016/S0309-1708(01)000070 .

Lite SJ, Bagstad KJ, Stromberg JC. 2005. Riparian plant species richness along lateral and longitud inal gradients of water stress and flood disturbance, San Pedro River, Arizona, USA. Jour nal of Arid Environments 63: 785-813. DOI:10.1016/j.jaridenv.2005.03.026

Lytle DA, Poff NL. 2004. Adaptation to natural flow regimes. Trends in Ecology and Evolution 19: 9 4-100. DOI: 10.1016/j.tree.2003.10.002

Maddock III T, Baird KJ. 2003. A riparian evapotranspiration package for Modflow-96 and Modflow-2 000. Department of Hydrology and Water Resources, University of Arizona. $60 \mathrm{p}$.

Maddock III T, Baird KJ, Hanson RT, Schmid W, Hoori A. 2012. RIP-ET: A riparian evapotranspirati on package for MODFLOW-2005. U.S. Geological Survey Techniques and Methods 6-A39, $76 \mathrm{p}$.

Mahoney JM, Rood SB. 1998. Streamflow requirements for cottonwood seedling recruitment: An inte grative model, Wetlands 18(4): 634- 645. DOI: 10.1007/BF03161678

McCree, K.J. (1972) The action spectrum, absorptance and quantum yield of photosynthesis in crop plants. Agricultural Meteorology, 9, 191-216.

Medici C, Wade AJ, Francés F. 2012. Does increased hydrochemical model complexity decrease ro bustness? Journal of Hydrology 440-441: 1-13. DOI: 10.1016/j.jhydrol.2012.02.047

Merritt DM, Scott ML, Poff NL, Auble GT, Lytle DA. 2010. Theory, methods and tools for determinin $\mathrm{g}$ environmental flows for riparian vegetation: riparian vegetation-flow response guilds. Fres hwater Biology 55(1): 206-225. DOI: 10.1111/j.1365-2427.2009.02206.x.

Montaldo N, Rondena R, Albertson JD, Mancini M. 2005. Parsimonious modeling of vegetation dyna mics for ecohydrologic studies of water-limited ecosystems. Water Resources Research 41: W10416. DOI: 10.1029/2005WR004094

Mouton AM, De Baets B, Goethals PLM. 2010. Ecological relevance of performance criteria for spe cies distribution models. Ecological Modelling 221(26): 1995-2002. DOI: 10.1016/j.ecolmodel .2010.04.017.

Nagler P, Glenn EP, Thompson TL, Huete A. 2004. Leaf area index and normalized difference vege tation index as predictors of canopy characteristics and light interception by riparian specie $\mathrm{s}$ on the Lower Colorado River. Agricultural and Forest Meteorology 125: 1-17. DOI: 10.1 016/j.agrformet.2004.03.008

Naiman RJ, Decamps H, McClain ME. 2005. Riparia: Ecology, Conservation and Management of St 
reamside Communities. Elsevier Academic Press, San Diego, Ca. 430p. ISBN:0-12-663315 $-0$

Naiman RJ, Latterell JJ, Pettit NE, Olden JD. 2008. Flow variability and the biophysical vitality of ri ver systems. Comptes Rendus Geoscience 340: 629-643. DOI: 10.1016/j.crte.2008.01.002

Naumburg E, Mata-Gonzalez R, Hunter RG, Mclendon T, Martin DW. 2005. Phreatophytic vegetation and groundwater fluctuations: a review of current research and application of ecosystem $r$ esponse modeling with an emphasis on Great Basin vegetation. Environmental Manageme nt, 35: 726-740. DOI: 10.1007/s00267-004-0194-7

Neff KP, Baldwin AH. 2005. Seed dispersal into wetlands: techniques and results for a restored tida I freshwater marsh. Wetlands 25(2): 392-404. DOI: 10.1672/14

Padilla FM, Pugnaire FI. 2007. Rooting depth and soil moisture control Mediterranean woody seedli ng survival during drought. Functional Ecology 21: 489-495. doi: 10.1111/j.1365-2435.2007. 01267.x

Pasquato M., Medici C., Friend A.D., Francés F. (2014). Comparing two approaches for parsimoniou $\mathrm{s}$ vegetation modelling in semiarid regions using satellite data. Ecohydrology. DOI:10.1002/ eco.1559

Perona P, Camporeale C, Perucca E, Savina M, Molnar P, Burlando P, Ridolfi L. 2009. Modelling ri ver and riparian vegetation interactions and related importance for sustainable ecosystem management. Aquatic Sciences 71: 266-278. DOI 10.1007/s00027-009-9215-1

Perucca E, Camporeale C, Ridolfi L. 2006. Influence of river meandering dynamics on riparian vege tation pattern formation. Journal of Geophysical Research 111: G01001. DOI: 10.1029/2005 JG000073

Polley, H. W., R. L. Phillips, A. B. Frank, J. A. Bradford, P. L. Sims, J. A. Morgan, and J. R. Kiniry (2011), Variability in light-use efficiency for gross primary productivity on Great Plains gra sslands, Ecosystems, 14(1), 15-27, DOI: 10.1007/s10021-010-9389-3.

Porporato A, Laio F, Ridolfi L, Rodríguez-Iturbe I. 2001. Plants in water controlled ecosystems: activ e role in hydrologic processes and response to water stress, III. Vegetation water stress. Advances in Water Resources 24: 725-744. DOI: 10.1016/S0309-1708(01)00006-9.

Quevedo D, Francés F. 2008. A conceptual dynamic vegetation-soil model for arid and semi-arid zo nes. Hydrology and Earth Systems Sciences 12: 1175-1187. DOI: 10.5194/hess-12-1175-20 08.

Raven PH, Evert RF, Eichhorn SE. 2012. Biology of Plants (8 $8^{\text {th }}$ Edition). W.H. Freeman and Company Publishers: New York. 880 pp. ISBN: 978-1464117800

Rodríguez-Iturbe I, Porporato A, Laio F, Ridolfi L. 2001. Plants in water controlled ecosystems: activ e role in hydrologic processes and response to water stress, I. Scope and general outline. Advances in Water Resources 24: 695-705. DOI: 10.1016/S0309-1708(01)00004-5.

Rood SB, Braatne JH, Hughes FM. 2003. Ecophysiology of riparian cottonwoods: stream flow depe ndency, water relations and restoration. Tree Physiology 23(16): 1113-1124. DOI: 10.1093/t reephys/23.16.1113.

Ryel R, Caldwell M, Yoder C, Or D, Leffler A. 2002. Hydraulic redistribution in a stand of Artemisia tridentata: evaluation of benefits to transpiration assessed with a simulation model. Oecologia, 130 (2): 173-184. DOI: $10.1007 / \mathrm{s} 004420100794$

Schenk HJ, Jackson RB. 2002. Rooting depths, lateral root spreads and below-ground/above-ground allometries of plants in water-limited ecosystems. Journal of Ecology 90: 480-494. DOI: 1 0.1046/j.1365-2745.2002.00682.x.

Scott RL, Goodrich DC, Levick LR. 2003. A Gis-Based Management Tool to Quantify Riparian Vege tation Groundwater Use. Proceedings First Interagency Conference on Research in the Wa tershed, Oct. 27-30, 2003. P. 222-227.

Sitch S, Smith B, Prentice IC, Arneth A, Bondeau A, Cramer W, Kaplan JO, Levis S, Lucht W, Syk es MT \& others. 2003. Evaluation of ecosystem dynamics, plant geography and terrestrial carbon cycling in the LPJ dynamic global vegetation model. Global Change Biology 9: 161 -185. DOI: 10.1046/j.1365-2486.2003.00569.x

Soeaert K, Hoffmann M, Meire P, Starink M, Van Oevelen D, Van Regenmortel S, Cox T. 2004. Mo deling growth and carbon allocation in two reed beds (Phragmites australis) in the Scheldt estuary. Aquatic Botany 79(3):211-234. DOI: 10.1016/j.aquabot.2004.02.001

Stevens LE, Waring LG. 1985. The Effects of Prolonged Flooding on the Riparian Plant Community in Grand Canyon. Paper presented at the Symposium on Riparian Ecosystems and their Management. University of Arizona, Tucson, April 16-18, 1985.

Stromberg JC, Patten DT. 1991. Instream flow requirements for cottonwoods at Bishop Creek, Inyo County, California (USA). Rivers 2:1-11.

Tabacchi E, Correll DL, Hauer R, Pinay G, Planty-Tabacchi AM, Wissmar RC. 1998. Development, maintenance and role of riparian vegetation in the river landscape. Freshwater Biology 40( 3): 497-516. DOI: 10.1046/j.1365-2427.1998.00381.x.

Tabacchi E, Planty-Tabacchi AM, Roques L, Nadal E. 2005. Seed inputs in riparian zones: implicati ons for plant invasion. River Research and Applications 21: 299-313. DOI: 10.1002/rra.848. 
Turner DP, Urbanski S, Bremer D, Wofsy SC, Meyers T, Gower ST, Gregory M. 2003. A cross-biom e comparison of daily light use efficiency for gross primary production. Global Change Biol ogy, 9: 383-395. DOI: 10.1046/j.1365-2486.2003.00573.x

Wade AJ, Hornberger GM, Whitehead PG, Jarvie HP, Flynn N. 2001. On modeling the mechanisms that control in-stream phosphorus, macrophyte, and epiphyte dynamics: an assessment of a new model using general sensitivity analysis. Water Resources Research 37: 2777-279 2. DOI: $10.1029 / 2000$ WR000115

Webb RH, Leake SA. 2006. Ground-water surface-water interactions and long-term change in riverin e riparian vegetation in the southwestern United States. Journal of Hydrology 320: 302-32 3. DOI: 10.1016/j.jhydrol.2005.07.022.

Woodward FI and Wolfgang C. 1996. Plant functional types and climatic changes: Introduction. Jour nal of Vegetation Science 7(3):306-308. DOI: 10.1111/j.1654-1103.1996.tb00489.x

Ye, F, Chen Q, Blanckaert K, Ma J. 2013. Riparian vegetation dynamics: insight provided by a proc ess-based model, a statistical model and field data. Ecohydrology 6: 567-585. DOI: 10.10 02/eco.1348

Yuan W, Liu S, Zhou G, Zhou G, Tieszen LL, Baldocchi D, Bernhofer C, Gholz H, Goldstein AH, G oulden ML, Hollinger DY, Hu Y, Law BE, Stoy PC, Vesala T, Wofsy SC, other AmeriFlux collaborators. 2007. Deriving a light use efficiency model from eddy covariance flux data $f$ or predicting daily gross primary production across biomes. Agricultural and Forest Meteor ology 143(3-4): 189-207. DOI:10.1016/j.agrformet.2006.12.001.

Zheng Z, Wang G. 2007. Modeling the dynamic root water uptake and its hydrological impact at the Reserva Jaru site in Amazonia. Journal of Geophysical Research, 112: G04012. DOI: 10.1029/2007JG000413. 